\title{
WestVirginiaUniversity
}

THE RESEARCH REPOSITORY @ WVU

Graduate Theses, Dissertations, and Problem Reports

2016

\section{Characterizations of the Marcellus Shale petrophysical properties}

Mohamed Elsaig

Follow this and additional works at: https://researchrepository.wvu.edu/etd

\section{Recommended Citation}

Elsaig, Mohamed, "Characterizations of the Marcellus Shale petrophysical properties" (2016). Graduate Theses, Dissertations, and Problem Reports. 5541.

https://researchrepository.wvu.edu/etd/5541

This Thesis is protected by copyright and/or related rights. It has been brought to you by the The Research Repository @ WVU with permission from the rights-holder(s). You are free to use this Thesis in any way that is permitted by the copyright and related rights legislation that applies to your use. For other uses you must obtain permission from the rights-holder(s) directly, unless additional rights are indicated by a Creative Commons license in the record and/ or on the work itself. This Thesis has been accepted for inclusion in WVU Graduate Theses, Dissertations, and Problem Reports collection by an authorized administrator of The Research Repository @ WVU. For more information, please contact researchrepository@mail.wvu.edu. 
Characterizations of the Marcellus Shale Petrophysical Properties

\title{
Mohamed Elsaig
}

Thesis submitted

to the Statler College of Engineering and Mineral Resources at West Virginia University

in partial fulfillment of the requirements for the degree of

\author{
Master of Science in \\ Petroleum and Natural Gas Engineering
}

Kashy Aminian, Ph.D., Chair

Samuel Ameri, M.S., P.E.

Mehrdad Zamirian, Ph.D.

Department of Petroleum and Natural Gas Engineering

\author{
Morgantown, West Virginia \\ 2016
}

Keywords: Shales, Steady-State Permeability Measurements

(C) Copyright 2016 Mohamed Elsaig 


\section{Abstract \\ Characterizations of the Marcellus Shale Petrophysical Properties}

\section{Mohamed Elsaig}

The application of horizontal drilling and hydraulic fracturing have made hydrocarbon production economically viable from the unconventional shale formations. Statistics show that currently, hydrocarbon production from shale formations play a major role in the overall production of hydrocarbon in the United States. However, the petrophysical characteristics of the shale, which influence the hydrocarbon recovery, and the optimization of hydraulic fracturing treatments have not been well established.

The characteristics of the unconventional formations, such as shale with ultra-low permeability, are often measured by unsteady-state techniques. The results of the unsteady state measurements, however, cannot be corrected for the pore and confining pressures and subsequently yield inconsistent values. In this research study, the porosity and the permeability of a Marcellus Shale core plug, obtained from a vertical well drilled at the Marcellus Shale Energy and Environment Laboratory (MSEEL) at a depth of 7547.03feet, have been measured using the Precision Petrophysical Analysis Laboratory (PPAL). PPAL utilizes highly accurate pressure and pressure-differential transducers and is capable of measuring the permeability in a nano-Darcy range under steady-state conditions. The entire system is enclosed in a clear Lexan container to assure temperature stability. PPAL allows a measurement to be performed on the core plug under confining pressure up to 10,000 psi and the pore pressure up to $1,500 \mathrm{psi}$.

In this study, the impact of the pore pressure and stress on the permeability and porosity of the Marcellus Shale core plug were evaluated. The pore pressure and stress were found to have a significant impact on the measured permeability values. Furthermore, the permeability exhibited hysteresis with increasing and decreasing stress values. The porosity measurements were not significantly impacted by the stress. Moreover, it was observed that the absolute permeability varies non-linearly with the stress due to the presence of fractures that play the dominant role in permeability of the shale. The porosity exhibited a linear relation with stress because the fractures do not significantly contribute to the porosity. The permeability measurements with Nitrogen were impacted by adsorption effects to a small degree. 


\section{Dedicated}

\section{To}

\section{My dear God}

Without Him guiding me in every step, nothing would be possible for me.

My parent (Ensaf Ahmed and Mamoun Elsaig)

I owe all of my achievements to them, whose presence would make this achievement even more special.

My sister (Samah) and my brother (Yosif)

Whose constant sacrifices to give me a better life and led me to this point.

My wife (Waad) and my son (Ahmed)

Everything I have achieved is because of you. 


\section{Acknowledgement}

I would like to express my deepest thanks and appreciations to my research advisor Dr. Kashy Aminian for his continuous support, assistance, and encouragement throughout this research. His contributions are numerous and valuable.

I strongly appreciate the support and advice from Professor. Sam Ameri, chair of Petroleum and Natural Gas Engineering Department. He has been father and friend throughout my study.

I would also like to thank the experts who were involved in my research Dr. Mehrdad Zamirian. Without his passionate participation and input, this research could not have been successfully conducted.

Furthermore, special thanks to all family of Petroleum and Natural Gas Engineering Department especially to Ms. Beverly Matheny for her friendly ambience and continuous help.

My Sincere appreciation also goes to my family and friends for their unconditional love, support, advice and prayers.

I cannot express enough love and appreciation for my beloved mother for her support. The reason of what I achieved today is because of you. 


\section{Table of Contents}

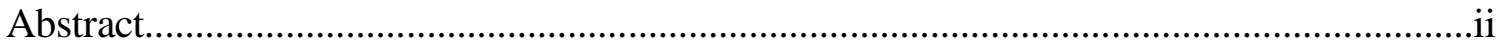

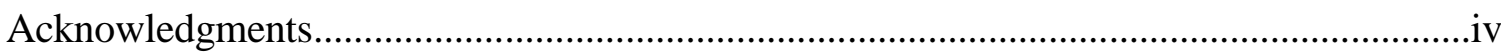

Chapter 1. Introduction ..........................................................................................

$1.1 \quad$ Problem Statement .........................................................................................

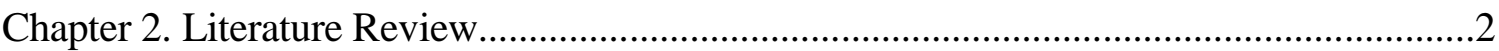

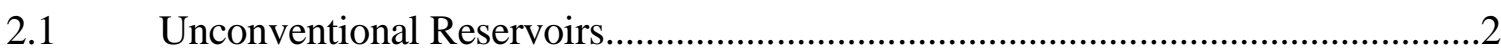

2.2 Precision Petrophysical Analysis Laboratory (PPAL)...........................................

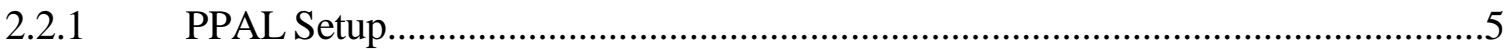

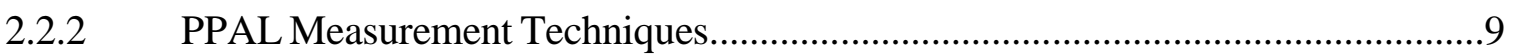

2.2.3 PPAL Experimental Protocols......................................................................15

Chapter 3. Objective and Methodology......................................................................18

3.1 Line Volume Measurement........................................................................18

3.2 Permeability Measurements ......................................................................18

3.3 Impact of the Pore Pressure on Permeability (Slippage Effect)............................21

$3.4 \quad$ Adsorption/Desorption Effect on Permeability................................................22

3.5 Stress Effect on Permeability and Porosity......................................................22

3.6 Fracture Closure Stress...............................................................................23

Chapter 4. Result and Discussion..................................................................................24

$4.1 \quad$ Permeability Measurements ............................................................................24

4.2 Impact of the Pore Pressure on Permeability (Slippage Effect).................................25

4.3 Absolute Permeability Determination.....................................................................2

4.4 Adsorption/Desorption Effect on Permeability.......................................................28

4.5 Stress Effect on Permeability and Porosity ............................................................28

4.6 Stress Effect on Absolute Permeability.............................................................30

4.7 Stress Induced Fractures.............................................................................................

4.8 Fracture Closure Pressure ..............................................................................34 


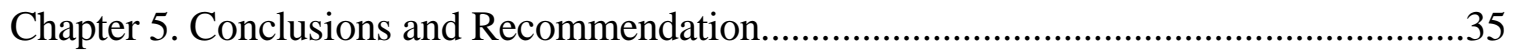

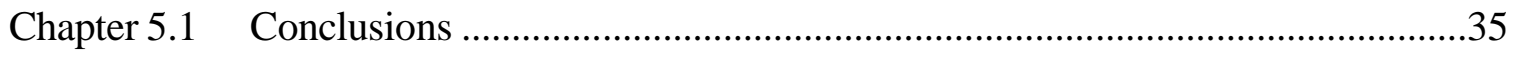

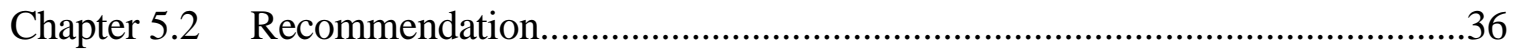

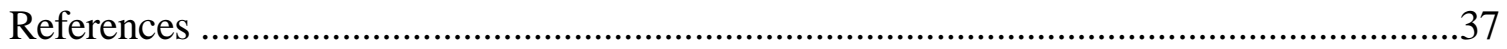

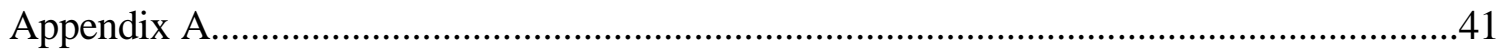

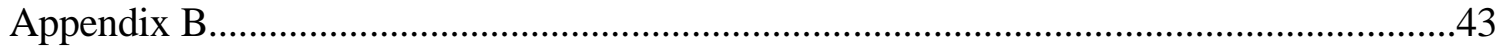

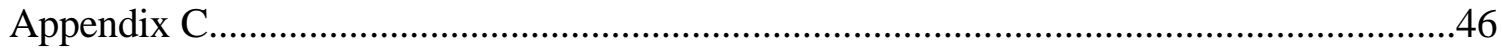

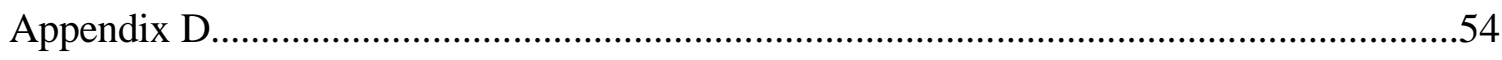




\section{List of Figures}

Figure 1: Gas Shale Basins in the United States.........................................................4

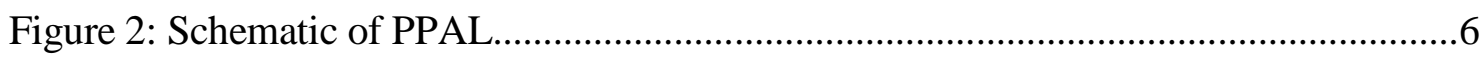

Figure 3: Core Holder Assembly and Core Plug Sample.................................................

Figure 4: Positive Displacement Hand Pump...............................................................8

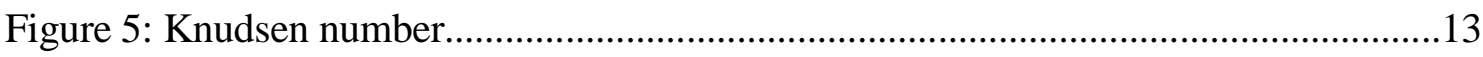

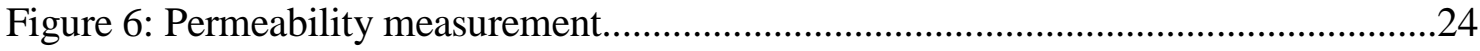

Figure 7: Gas pressure (slippage) effect on permeability using Helium...........................26

Figure 8: Gas pressure (slippage) effect on permeability using Nitrogen.........................26

Figure 9: Klinkenberg correction on gas permeability measurements.............................27

Figure 10: Double slippage correction on gas permeability using Helium.......................27

Figure 11: Adsorption/Desorption Effect on Permeability.............................................28

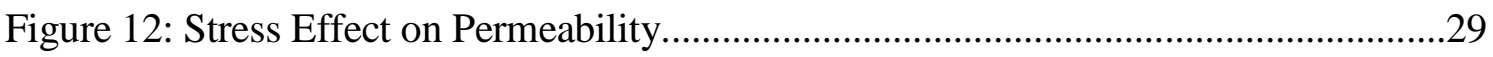

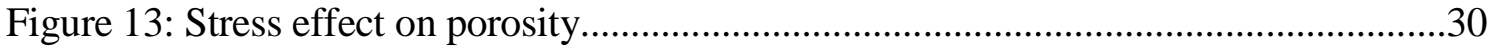

Figure 14: Absolute permeability by double slippage correction under stress condition ...32

Figure 15: Stress effect on Absolute Permeability........................................................32

Figure 16: Double slippage correction (N2 Desorption before and after relaxation).........33

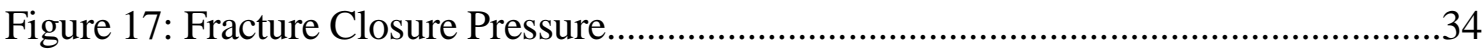




\section{List of Tables:}

Table 1: Comparison of Data for the Gas Shale in the United States...................................

Table 2: Permeability Measurements Plan........................................................................19

Table 3: Statistical analysis for Permeability Measurement.............................................25

Table 4: The Measured Permeability Values at Different Gas Pressures.............................25

Table 5: Effect of stress on permeability and porosity......................................................29

Table 6: Stress Effect on Absolute Permeability...............................................................

Table 7: Double slippage correction $\left(\mathrm{N}_{2}\right.$ Desorption before and after relaxation) ...............33 


\section{Chapter 1 \\ Introduction}

\subsection{Problem Statement}

The petrophysical properties of the unconventional reservoirs, including permeability and porosity along with adsorption characteristics, are the keys to estimating the original gas-inplace, predicting the production rates, and optimizing the hydraulic fracturing treatments.

Determination of the petrophysical properties of a shale reservoir is challenging due to the complex nature of the shale gas reservoirs. Shale gas reservoirs properties include TOC, mineralogy and lithology, pore/throat geometry, texture, anisotropy and heterogeneity, natural fracture network, rock mechanical property heterogeneities and in-situ stress distributions, faults/karsts and structure impact, and production operation interaction with the reservoir (Du et al. 2011). The permeability of conventional reservoirs can be accurately and rapidly measured by the steady-state laboratory techniques. These techniques however are not practical for the unconventional shale formations due to the long time required to reach the steady and difficulties in measuring extremely low flow rates.

On the other hand, unsteady state techniques such as GRI and pressure pulse decay, could measure the permeability values as low as $10^{-9}$ Darcy, and have been extensively used to determine the permeability of the shale. However, the unsteady state measurements results cannot be corrected for the pore pressure or stress and subsequently yield inconsistent values (Sondergeld et al. 2010; Tinni et al., 2012; Zamirian et al. 2014a). Therefore, as stated before, the limitations of these techniques has led to the development of a new approach to measure the characterizations and petrophysical properties of the unconventional reservoir, which is the Precision Petrophysical Analysis Laboratory (PPAL). The impact of pore and confining pressures on the porosity and the permeability of the Marcellus Shale will be investigated using PPAL setup in this study. 


\section{Chapter 2}

\section{Literature Review}

\subsection{Unconventional Reservoirs}

Unconventional natural gas is defined as (Holditch, 2007): "natural gas that cannot be produced at economic flow rates nor in economic volumes of natural gas, unless the well is stimulated by a large hydraulic fracture treatment, a horizontal wellbore, or by using multilateral wellbores or some other technique to expose more of the reservoir to the wellbore".

Under normal circumstances, an unconventional gas reservoir could be deep or shallow; high pressure or low pressure; high temperature or low temperature; homogeneous or naturally fractured; and containing a single layer or multiple layers. The unconventional reservoir's profitability is dependent on the optimum drilling, completion, and stimulation methods for each well. Considerable research shows that unconventional gas reservoirs in southern Texas might have properties that are markedly different from those in South America or the Middle East. These differences are connected to the cost of production, especially drilling costs, completion, and stimulation of these wells, as well as the gas price and the gas market affects how tight-gas reservoirs are developed (Schenk, 2002).

The importance of unconventional natural gas formations cannot be overemphasized as unconventional natural gas formation such as the Marcellus Shale have become an increasingly important source of natural gas in the United States, since the beginning of the twenty-first century. The prevalence of hydraulic fracturing and horizontal drilling have made it possible for the unconventional reservoir to be economically productive. From 2000 to 2010, the shale gas contribution to the United States natural gas production rose from only one percent to over 20 percent. In fact, the Energy Information and Administration (EIA) predicts that by 2040, 53 percent of the United States natural gas supply will come from shale gas (EIA, 2012). 
One of the largest contributor to shale production in the United States is the Marcellus Shale in West Virginia, Pennsylvania, Ohio, and New York. Table 1 summarizes the general properties of the shale basins in the United States and Figure 1 illustrates shale gas basins in the United States.

Table 1 - Comparison of Data for the Gas Shale in the United States (Daniel, 2009)

\begin{tabular}{|c|c|c|c|c|c|c|c|}
\hline \multicolumn{8}{|c|}{ EXHIBIT 3. COMPARISON OF DATA FOR THE GAS SHALES IN THE UNITED STATES } \\
\hline Gas Shale Basin & Barnett & Fayetteville & Haynesville & Marcellus & Woodford & Antrim & New Albany \\
\hline $\begin{array}{l}\text { Estimated Basin } \\
\text { Area, square miles }\end{array}$ & 5,000 & 9,000 & 9,000 & 95,000 & 11,000 & 12,000 & 43,500 \\
\hline Depth, ft & $\begin{array}{l}6,500- \\
8,500^{10}\end{array}$ & $\begin{array}{l}1,000- \\
7,000^{10}\end{array}$ & $\begin{array}{l}10,500- \\
13,500^{11}\end{array}$ & $\begin{array}{l}4,000- \\
8,500^{1}\end{array}$ & $\begin{array}{l}6,000- \\
11,000^{10}\end{array}$ & $\begin{array}{l}600- \\
2,200^{10}\end{array}$ & $\begin{array}{c}500- \\
2,000^{10}\end{array}$ \\
\hline Net Thickness, $\mathrm{ft}$ & $\begin{array}{l}100- \\
600^{10}\end{array}$ & $20-200^{10}$ & $200^{10}-300$ & $50-200^{12}$ & $120-220^{13}$ & $70-12^{10}$ & $50-100^{10}$ \\
\hline $\begin{array}{l}\text { Depth to Base of } \\
\text { Treatable Water, } \mathrm{ft}\end{array}$ & $\sim 1200$ & $\sim 500^{14}$ & $\sim 400$ & $\sim 850$ & $\sim 400$ & $\sim 300$ & $\sim 400$ \\
\hline $\begin{array}{l}\text { Rock Column } \\
\text { between Pay and } \\
\text { Base of Treatable } \\
\text { Water }\end{array}$ & $\begin{array}{c}5,300- \\
7,300\end{array}$ & $500-6,500$ & $\begin{array}{c}10,100- \\
13,100\end{array}$ & $\begin{array}{c}2,125- \\
7,650\end{array}$ & $\begin{array}{l}5,600- \\
10,600\end{array}$ & $\begin{array}{l}300- \\
1,900\end{array}$ & $100-1,600$ \\
\hline $\begin{array}{l}\text { Total Organic } \\
\text { Carbon, \% }\end{array}$ & $4.5^{10}$ & $4.0-9.8^{10}$ & $0.5-4.0^{11}$ & $3-12^{15}$ & $1-14^{16}$ & $1-20^{10}$ & $1-25^{10}$ \\
\hline Total Porosity, \% & $4-5^{10}$ & $2-8^{10}$ & $8-911$ & $10^{17}$ & $3-918$ & 910 & $10-14^{10}$ \\
\hline $\begin{array}{l}\text { Gas Content, } \\
\text { scf/ton }\end{array}$ & $\begin{array}{l}300- \\
350^{10}\end{array}$ & $60-220^{10}$ & $100-330^{19}$ & $60-100^{17}$ & $200-300^{20}$ & $40-100^{10}$ & $40-80^{10}$ \\
\hline $\begin{array}{l}\text { Water Production, } \\
\text { Barrels water/day }\end{array}$ & $0^{10}$ & 0 & 0 & 0 & & $5-500^{10}$ & $5-500^{10}$ \\
\hline Well spacing, Acres & $60-160^{10}$ & $80-160$ & $40-560^{21}$ & $40-160^{21}$ & $640^{21}$ & $40-160^{10}$ & $80^{10}$ \\
\hline $\begin{array}{l}\text { Original Gas-In- } \\
\text { Place, Tcf22 }\end{array}$ & 327 & 52 & 717 & 1,500 & 52 & 76 & 160 \\
\hline Reserves, Tcf22 & 44 & 41.6 & 251 & $\begin{array}{l}363^{23}, \\
50024\end{array}$ & 11.4 & 20 & 19.2 \\
\hline $\begin{array}{l}\text { Est. Production, } \\
\mathrm{mcf} / \text { day/well }\end{array}$ & 33824 & $530^{24}$ & $\begin{array}{c}625- \\
1,800^{25}\end{array}$ & $3,100^{26}$ & $415^{24}$ & $125-200^{24}$ & \\
\hline \multicolumn{8}{|c|}{$\begin{array}{l}\text { mcf }=\text { thousands of cubic feet of gas. } \\
\text { NoTE: Data derived from various sources and research analysis. Information from some basins was unable to be identified and confirmed at the } \\
\text { time of this paper and has been left blank. } \\
\# \text { * for the Depth to base of treatable water data, the data was based on depth data from state oil and gas agencies and state geological survey data. }\end{array}$} \\
\hline
\end{tabular}




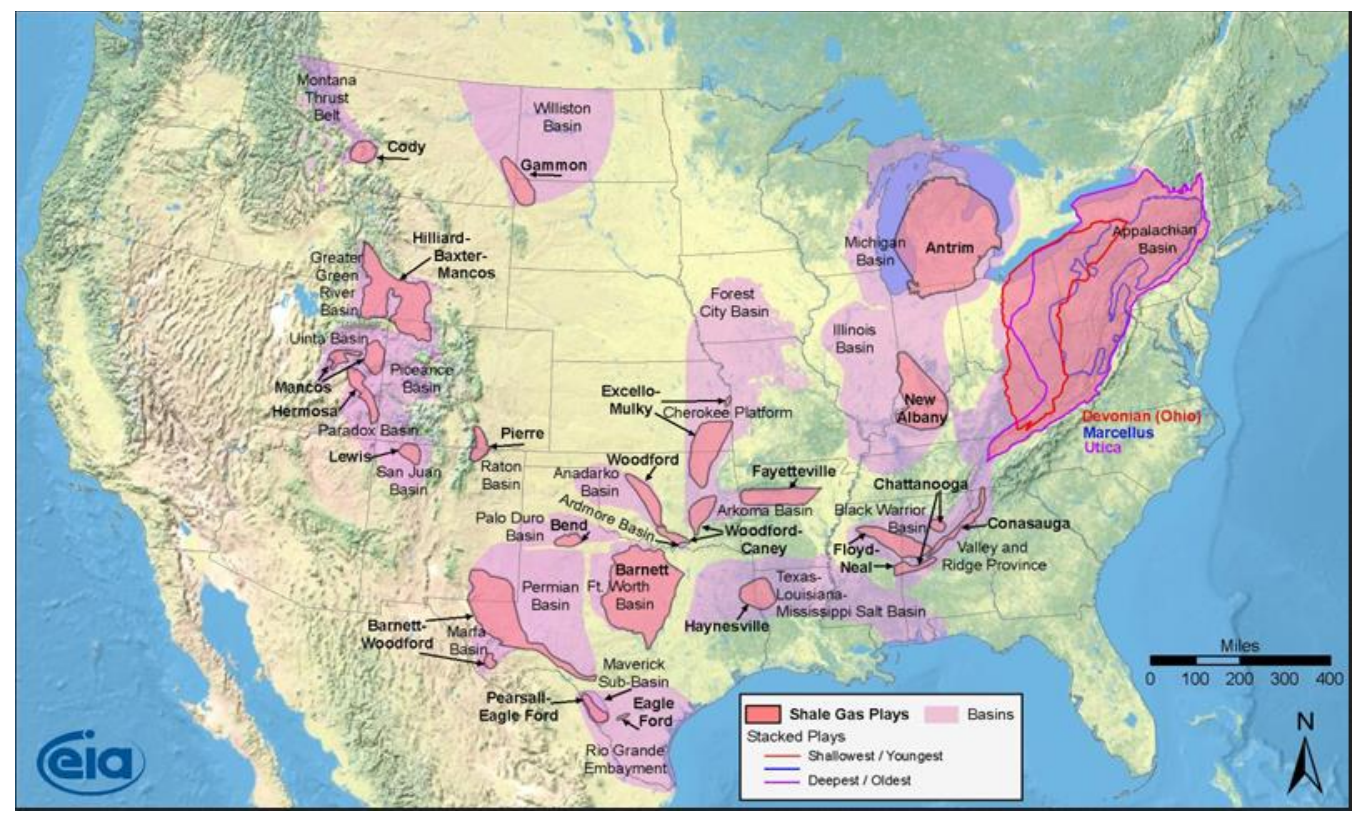

Figure 1. Gas Shale Basins in the United States (EIA, 2011)

\subsection{Precision Petrophysical Analysis Laboratory (PPAL)}

The Precision Petrophysical Analysis Laboratory (PPAL) inspired from the CORAL and modified by using the latest software technology and parts. The Institute of Gas Technology (IGT) in the 1980's had a project called the Computer Operated Rock Analysis Laboratory or CORAL (Soeder, 1988) to measure the porosity and permeability of the Devonian gas sands, which is a tight sandstone. The CORAL frame was constructed of wood, and all the valves had to be controlled manually. The CORAL recorded data at that time by using a basic computer. PPAL is built in a closed box and modified with electric heaters, programmable temperature controller, and circulation fans to eliminate the temperature change during the experiments. The PPAL frame was built with aluminum and clear Lexan to enable visibility inside the box. Moreover, all valves, such as pneumatic and electric valves, and pressure-differential transducers are automatic and controlled by a computer to eliminate any human error and to avoid any change of temperature during the experiments. 
Zamirian et al., (2014b) conclude the advantage of the PPAL are:

1. Its valves are automatic and controlled by a computer to eliminate any human error.

2. Has the capabilities of simulating reservoir conditions such as pore pressure, overburden pressure, temperature and steady-state gas flow through the core plug.

3. Has highly accurate pressure transducers with the resolution of 0.001 psi.

4. Is capable of measuring the permeability with an accuracy of a nano-darcy and the porosity with an accuracy of $\sim 0.1 \%$

5. It can provide fast, repeatable, and consistent results.

6. Has ability to monitor the flow rate during the experiment to know when the sample is fully saturated (adsorbed or desorbed)

7. It can correct the measured permeability for the pore and confining pressures.

\subsubsection{PPAL Setup}

When applied in this process this multi-task machine can be built and modified in a way that measures porosity, adsorption characteristics, and permeability with modified steady-state techniques. Therefore, the apparatus is enclosed in a compact box with electric heaters, programmable temperature controller, and circulation fans are mounted to maintain the steady temperature during the process of the experiment. Figure 2 illustrate the Schematic of PPAL component as consist of the following:

1. Core Holder.

2. Air and Water Supply (Confining Pressure).

3. Two One-Gallon Gas Tanks.

4. Pneumatic Valves (PV), and Electric Valves (V).

5. Differential-pressure transducer (MDP), and Ultra-precise differential-pressure transducers (UDPT).

6. Manual Pressure Generator 


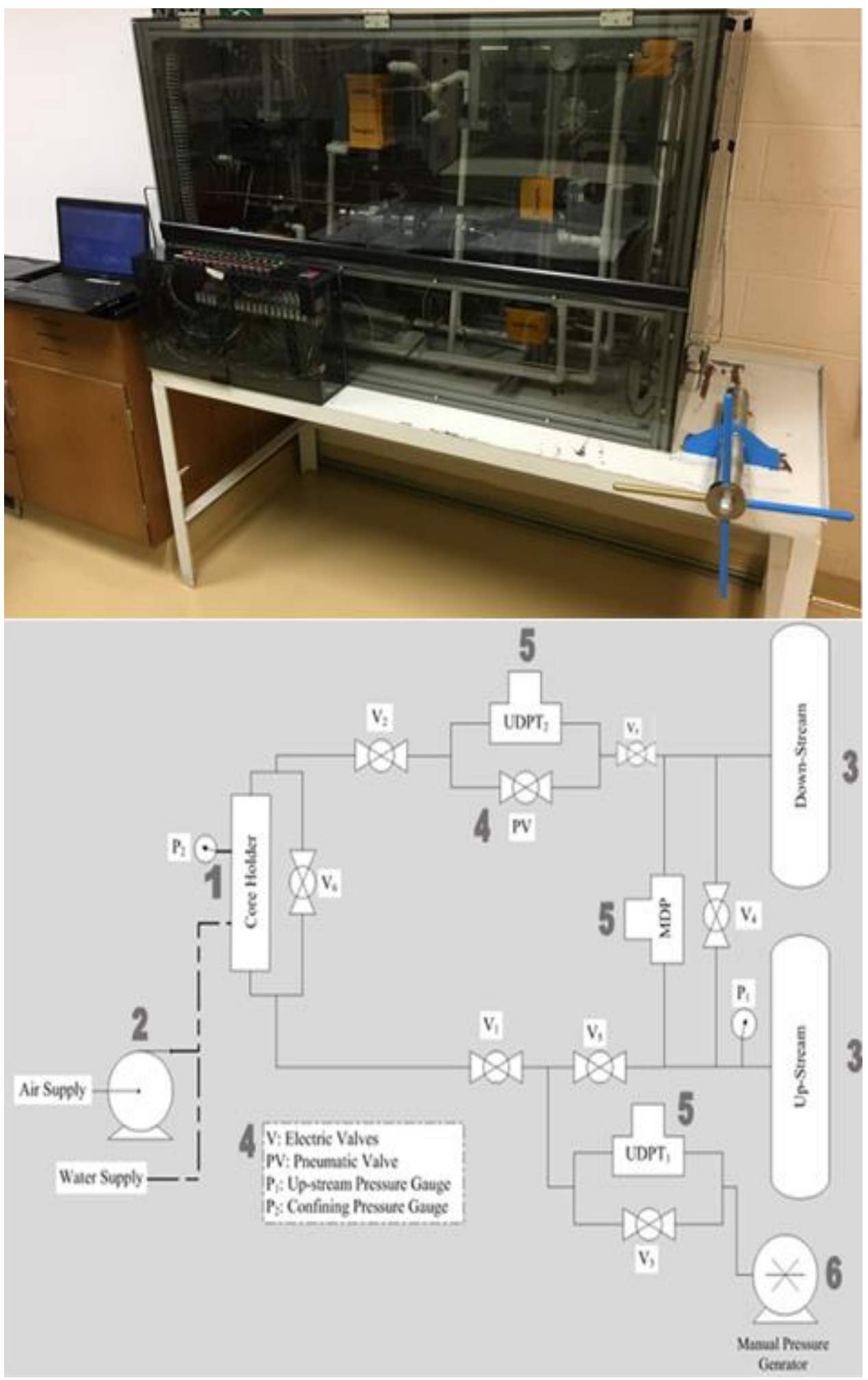

Figure 2: Schematic of PPAL 


\subsubsection{Core Holder}

Figure 3 illustrates details of the core holder, which include fixed and floating ends and the rubber sleeve (Dalton, 2012). The core holder is a solid stainless steel instrument positioned in the center of the unit. However, it allows the unit to warm evenly and maintains a constant and steady temperature. The core holder holds plugs with a diameter of one inch and length from one to three inches. The core sample is placed in the sleeve, which is made of Viton Synthetic Elastomer. Therefore, the sleeve could separate the sample from the water.

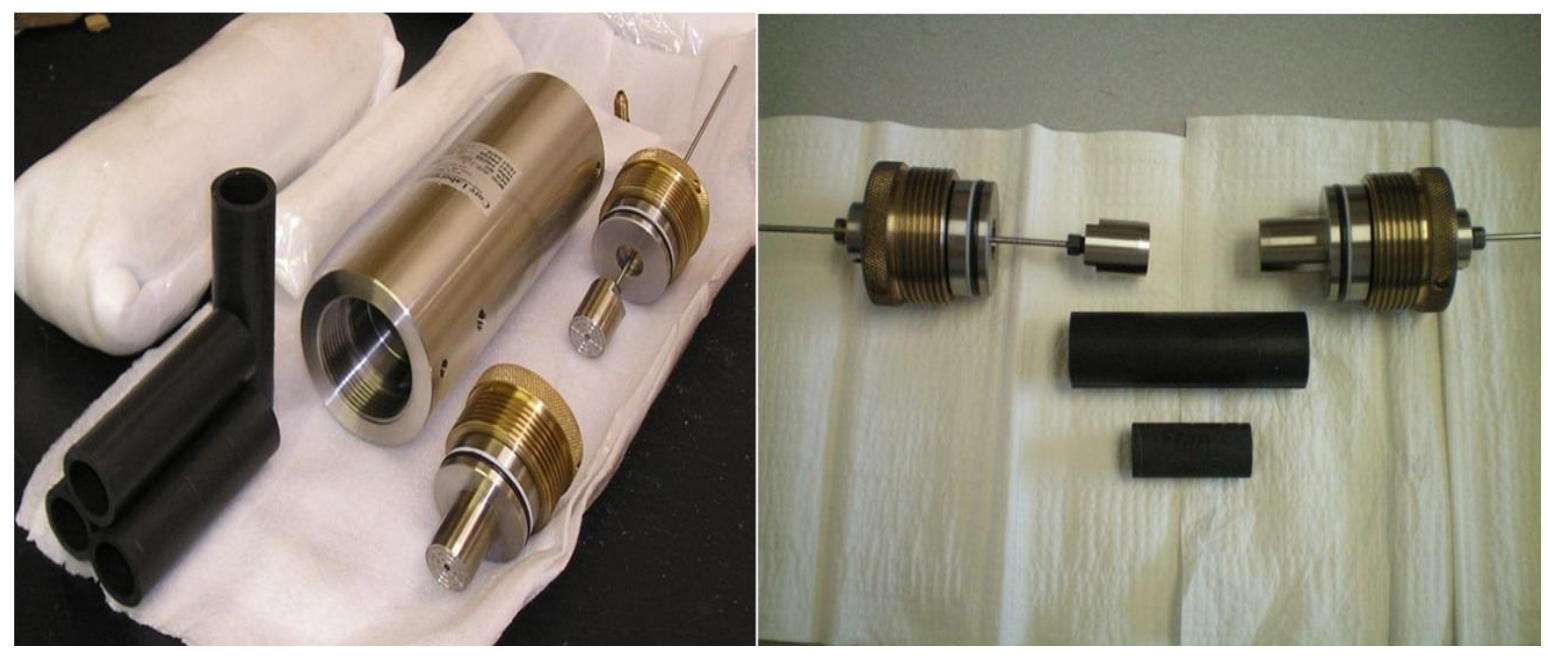

Figure 3: Core holder assembly and a 2-inch long core plug sample (Dalton, 2012)

\subsubsection{Air and Water Supply (Confining Pressure)}

In this process, we use an air driven liquid pump to pressure the water to a maximum of a 10,000 psi. This confining pressure is going to be connected to a transducer which records pressure with an accuracy of one psi.

\subsubsection{Two One-Gallon Gas Tanks}

The two one-gallon gas tanks function as gas storage for the upstream and downstream pressure by way of connecting them (two one-gallon gas tanks) to upstream and downstream ends of the core holder. At the volume of the tanks, they are sufficient to keep the pressure at a steady level during experiments at the end of both core holder, by connecting the upstream tank to a pressure transducer which records pressure up to $1,500 \mathrm{psi}$, with an accuracy of 0.75 psi. 


\subsubsection{Pneumatic Valves (PV), and Electric Valves (V)}

Pneumatic valve is provided by a gas and fluid system components company, Swagelok, which provides electric actuators that are used in the ball valve. On the other hand, the electrical valve which operates through the Lab view software system. However, both valves maintain the operation process, stabilizes the steady operational temperature of the unit, as well as preventing interference with the unit to eliminate any human error.

\subsubsection{Differential-pressure transducer (MDP), and Ultra-precise differential- pressure transducers (UDPT)}

The Differential-pressure transducer (MDP) with an accuracy of 0.2 psi records the difference between the upstream and the downstream tanks. The Ultra-precise differentialpressure transducers (UDPT) are connected to both the upstream and the downstream valves and can measure pressure differentiation of up to 0.5 psi with a measurement accuracy of $5 \times 10^{-4}$ psi.

\subsubsection{Manual Pressure Generator}

The manual positive displacement pump is connected at the end of the Pressure differential transducer (UDPT), which is used in supplying gas for the volume measurement.

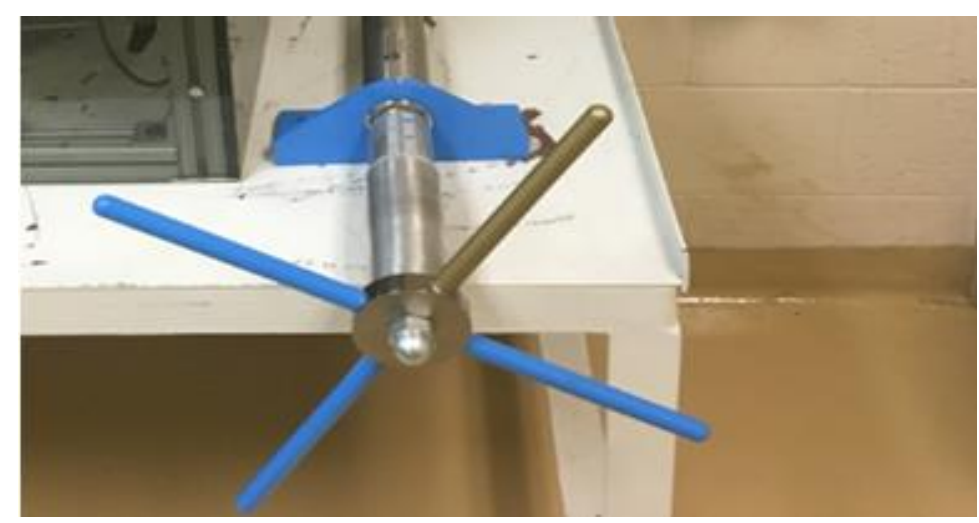

Figure 4: Positive Displacement Hand Pump

The control valves, electric actuators, sensitive pressure and pressure differential transducers are used in the automatic control of the flow and monitoring of pressures. The data acquisition system, relays, and a computer with a Lab view software system are used in the operation of the PPAL system to collect data. However, for more information of the PPAL component specifications could be found in (Dalton, 2012). 


\subsubsection{PPAL Measurement Techniques}

\subsubsection{Line Volume Measurement}

Zamirian (2015) derived an equation to estimate the line volume based on Boyle's law as shown in appendix A.

$$
V_{D}=\Delta V \frac{P_{U} Z_{D}}{P_{U} Z_{D}-P_{D} Z_{U}}
$$

\section{Where:}

$\mathrm{V}_{\mathrm{D}}$ : Volume of the line.

$\Delta \mathrm{V}$ : Volume of the gas displaced by the positive displacement pump.

$\mathrm{P}_{\mathrm{U}}$ Upstream pressure, psi.

$\mathrm{P}_{\mathrm{D}}$ Downstream pressure, psi.

$\mathrm{Z}_{\mathrm{U}}$ : Upstream compressibility factor.

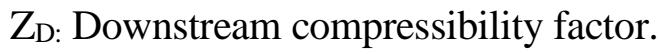

\subsubsection{Porosity Measurement}

The same line volume measurement can be done except the blank is replaced with the core sample, and the difference between the volume $\left(\mathrm{V}_{\mathrm{D}}\right)$ calculated by the sample and the blank yields the pore volume. For porosity calculation, it is sufficient to consider the pore volume of the sample, which is added to the line volumes and can be calculated as:

$$
V_{p}=\Delta V \frac{P_{U} Z_{D}}{P_{U} Z_{D}-P_{D} Z_{U}}-V_{D}
$$

\section{Where:}

$\Delta \mathrm{V}$ : Volume of the gas displaced by the positive displacement pump.

$V_{\mathrm{P}}$ : Pore volume of the sample.

$\mathrm{P}_{\mathrm{U}}$ Upstream pressure, psi.

$\mathrm{P}_{\mathrm{D}}$ : Downstream pressure, psi.
$\mathrm{V}_{\mathrm{D}}$ : Volume of the line.

$\mathrm{Z}_{\mathrm{U}}$ : Upstream compressibility factor.

$\mathrm{Z}_{\mathrm{D}}$ : Downstream compressibility factor. 


\subsubsection{Permeability Measurement}

The permeability of the sample could be measured by the use of pressure difference in the sample by allowing the gas to flow. When gas flows from the upstream tank through the core sample accumulates in the small line on the downstream side of the core holder and connects to an automated valve (PV). The (PV) valve works automatically when the pressure difference across the valve reaches a certain value (Set the software for pressure difference across the valve $0.4 \mathrm{psi}$ ). The difference between the small line and the downstream is measured with an ultra-precise differential pressure transducer (UDPT2), which has a maximum limit of 0.5 psi pressure differential. Meanwhile, when the gas accumulates in the downstream line, the pressure difference increases, and once the pressure reaches $0.4 \mathrm{psi}$, the PV valve will open automatically to release the pressure. The valve stays open until the pressure in the line equalizes in the downstream pressure. After that, the PV valve closes to build the pressure up again and allows the test to be repeated, as many times as needed. Since the upstream pressure is constant during the test and downstream pressure builds up no more than $0.4 \mathrm{psi}$, the flow can be considered to be steady-state. The flow rate is then determined based on the mole balance, duration of the test, and the measured pressure differential. The accuracy of the pressure transducers allows the flow rates as low as $10^{-6} \mathrm{~cm}^{3} / \mathrm{s}$ to be determined accurately. The data acquisition system records the pressure buildup in the line over time, and the software uses the results to determine the flow rate on a real time basis. That allows the flow rate to be monitored continuously throughout the experiment. The permeability of the sample under the set conditions (temperature, confining pressure, pore

pressure) is then determined by Darcy's equation. (Zamirian, 2015) derived an equation to calculate the permeability as shown in appendix B.

$$
k=\frac{2 \mu L V_{L+p} U D P T_{2}}{A \Delta t\left(P_{U}^{2}-\left(P_{D}+U D P T_{2}\right)^{2}\right)}
$$




\section{Where:}

$K \quad$ : Permeability, Darcy

$\mathrm{V}_{\mathrm{L}+\mathrm{P}}$ : Total volume of the downstream section $\left(\mathrm{V}_{6}\right.$ to $\left.\mathrm{PV}\right)$ plus the sample pore volume.

$U D P T_{2}$ : Pressure builds up, atm

$\mu \quad$ : Viscosity, cp

$L \quad$ : Length of the plug, $\mathrm{cm}$

A : Cross section area of the plug, $\mathrm{cm}^{2}$

$P_{D} \quad$ : Down-stream absolute pressure, atm

$P_{U} \quad:$ Up-stream absolute pressure, atm

$\Delta \mathrm{T} \quad$ : Time, second.

\subsubsection{Steady-State Flow Rate Validation}

The objective of building PPAL is to measure shale permeability, which in the range of nano-darcy under a steady-state condition. Therefore, validating the steady-state flow rate across the sample is crucial as a proof of concept. The pressure drop across the sample staying constant over time is a one-dimensional steady-state condition based on Darcy's law (Tarek, 2010). PPAL has two one-gallon gas tanks functions as gas storage for the upstream and downstream pressure, by way of connecting them to the upstream and downstream ends of the core holder to keep the sufficient pressure at a steady level during experiments. Also, connecting the UDPT2 at downstream allows the pressure to build up a maximum 0.5 Psi in the downstream and then releases the gas to maintain the constant downstream pressure and the steady-state condition. Darcy's law is valid when the flow is linear (Darcy, 1856). Therefore, the linear pressure builds up at UDPT2 indicates a linear flow of gas through the sample which allows us to apply Darcy's law to calculate the permeability. 


\subsubsection{Klinkenberg Correction}

Klinkenberg (1941) demonstrated that the permeability of porous media to gasses is a linear function of the mean reciprocal pressure as shown in Equation 2-4:

$$
\begin{gathered}
k_{g}=k_{\infty}\left(1+\frac{b_{k}}{\bar{p}}\right) \\
\frac{b_{k}}{\bar{p}}=\frac{4 c \lambda}{r}
\end{gathered}
$$

\section{Where:}

$k_{\infty}$ : absolute (liquid) permeability

$b_{k}$ : slippage factor

$\lambda$ : mean free path of gas molecules, $\mathrm{mm}$.

$r$ : radius of a capillary or a pore, $\mathrm{mm}$.

Klinkenberg's theory considers the momentum carried by the gas molecules hitting the pore walls, gas slippage, which results in higher gas rates and ignores the momentum that gas molecules can carry to the bulk fluid. Moreover, using the focused ion beam scanning electron microscopy (FIB/SEM) has shown that two distinct porous media exists in organicrich shale, i.e. Organic and Inorganic (Ambrose, 2010). A significant portion of the pores associated with gas storage is found within organic materials, or kerogen pockets, which are 200-500 nanometers (nm) in size. The pores in these kerogen pockets are in the range of microspore (less than $2.0 \mathrm{~nm}$ ), and mesopore $(2-50 \mathrm{~nm}$ ) sizes with the average pore size below $10 \mathrm{~nm}$ (Adesida, 2011). The pore size range indicates that; the organic-rich shale can be considered as a naturally occurring nano-pore material. At this scale, the classical approach of modeling gas flow based on continuum equations may not be valid. Different flow regimes are categorized based on Knudsen number (Roy, 2003): 
1. Continuum (viscous) flow $\left(K_{n}<0.001\right)$.

2. Slip flow $\left(0.001<K_{n}<0.1\right)$.

3. Transition flow $(0.1<K n<10)$ : In this regime, a combination of slip and diffusion flow occurs.

4. Free molecular flow $(K n>10)$.

Where Knudsen number $(\mathrm{Kn})$ as illustrate in Figure 4, is defined as the ratio of molecular mean free path to a characteristic length of pores $(\mathrm{L})$ :

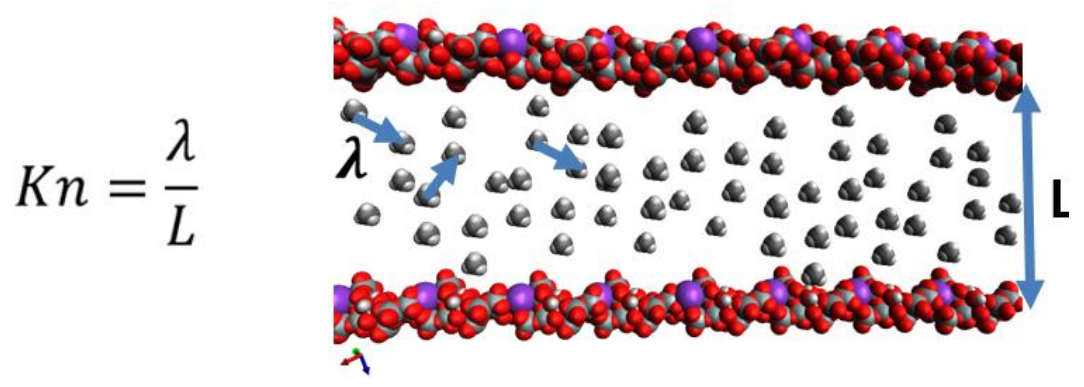

Figure 5: Knudsen Number

\subsubsection{Double Slippage Correction}

Recently, Fathi (2012) incorporated the momentum carried by bouncing back molecules was into the slip flow leading to a linear relation between permeability and reciprocal of square of pressure (double slippage correction) as follows:

$$
k_{g}=k_{\infty}\left[1+\left(\frac{b_{k}}{p}\right)^{2} \frac{L_{K e}}{\lambda}\right]
$$

Where $L_{K e}$ is a length scale associated with the kinetic energy of the bouncing-back molecules. The double-slippage affect can lead to measured permeability values that are even higher than those predicted by Klinkenberg theory at low pressures. Others have observed this phenomenon where the higher gas flow was inadvertently attributed to turbulent flow in nano-pores at low pressures (Rushing, 2004), while the impact of the turbulent flow in shale due to a very low Reynolds number is negligible as compared to gas slippage effects at low pressures (Wu, 1998). 
Ashish (2016) conduct a set of experiments to characterize the flow regime in shales for gas permeability measurements over different pore pressure ranges and conclude:

1. Pore pressure $\leq 250 \mathrm{psi}$; transition flow is dominant and double slippage correction are required.

2. Pore pressure $\approx 1000$ psi; slip flow is prevalent and Klinkenberg correction can be used to determine the absolute permeability

3. Pore pressure $\geq 2000 \mathrm{psi}$; the correction in permeability values is negligible.

\subsubsection{Effect of Stress on the Porosity and Permeability}

The reason for these different behaviors can be related to the nature of the shale. Shale is known as naturally fractured formations. Beside the fractures, shale contains organic material known as kerogen in their matrix media. Thus, each media has its porosity and permeability. Generally speaking, a permeability of fracture is higher than a permeability of the matrix due to the higher conductivity in fractures, while porosity of the matrix is greater than the porosity of fracture due to its higher storage capacity. In other words, when a sample, which is a combination of these two media, undergoes porosity and permeability tests, matrix plays the dominant role in porosity measurement, while the fracture plays the dominant role in permeability measurement. By knowing this, it can be explained that porosity did not show hysteresis because pores in the matrix media have not lost their volume, and grains are not damaged or crushed. On the other hand, the fractures, which play the dominant role in permeability, did not open completely after the stress was released, which caused permeability hysteresis (Zamirian, 2015). In regard to (Walsh J. B., 1981), the relationship between both porosity and permeability versus stress, especially in fractured formations, should be a power law, exponential, logarithmic or even polynomial due to the fractures that play the dominant role in total permeability of the rock. Zamirian et al. (2015a) was performed a set of experiments on the shale sample to investigate the effect of stress on porosity and permeability. However, results show permeability is very sensitive to stress while porosity is impacted by stress to a lesser extent. Also, the impact of stress on permeability is an irreversible process but permeability will not return to its initial value. 


\subsubsection{Walsh Plot}

Walsh plot provides a procedure to check when the fracture is closed by plotting $\left(k / k_{o}\right)^{1 / 3}$ vs. $\operatorname{Ln}\left(P / P_{o}\right)$, where $k$ is the permeability at the stress $P$ and $k_{0}$ is the permeability at the lowest stress $\left(P_{o}\right)$. However, the point where the slope of the straight line is changed is the point where the fracture is closed. In other words, the first straight line represents the pressures where the fractures are open and the second straight line represents the pressures where the fractures are completely closed (Walsh J. B., 1984).

\subsubsection{PPAL Experimental Protocols}

\subsubsection{Loading a Sample Procedure}

In this section provides step-by-step procedure to load a sample (Refer to Figure 2):

1. Remove the fixed end of the core holder and the large rubber O-ring, then lubricate with a thick, clean, petroleum jelly.

2. Place the core plug sample in the sleeve. Then, insert the free end of the core holder into the sleeve so that it comes in contact with the core plug sample. This assembly is then fitted into the core holder body. After the plug is placed into the core holder, both ends of the core holder can be screwed in completely.

3. Open the water line to allow water to pass through the confining pump to pressurize the core holder with the desired confining pressure.

4. If no water leaks from the gas line system (the core holder is completely isolated from the gas line), then connect and screw both ends of the core holder to the gas line completely.

5. The gas is then pressurized into the tanks and the rest of the system. (If this is the first time, the gas has to be Helium as a non- adsorbent gas).

\subsubsection{Line Volume Procedure}

For the purpose of the line volume measurements, a blank instead of a core sample is loaded in the core holder. If no leakage is detected upon applying confining pressure, the following steps must be taken (Refer to Figure 2): 
1. Close valves $\mathrm{V}_{1}$ and $\mathrm{V}_{4}$ to separate upstream from downstream.

2. Open valves $\left(\mathrm{V}_{2}, \mathrm{~V}_{3}, \mathrm{~V}_{5}, \mathrm{~V}_{6}, \mathrm{~V}_{7}\right.$, and $\left.\mathrm{PV}\right)$ to charge downstream section $\left(\mathrm{V}_{1}\right.$ to $\mathrm{V}_{2}$ through $V_{6}$, called $\left.V_{D}\right)$ with downstream pressure $P_{D}$, and to charge upstream section $\left(V_{3}\right.$ to $V_{5}$, called $\mathrm{V}_{\mathrm{U}}$ ) with upstream pressure $\mathrm{P}_{\mathrm{U}}$.

3. Pressurize the entire system to the desired downstream pressure $\left(\mathrm{P}_{\mathrm{D}}\right)$ by using MDP (partial differential transducer). Then close the valve $\left(\mathrm{V}_{4}\right)$ between the two tanks.

4. Pressurize the upstream tank to the desired value $\left(\mathrm{P}_{\mathrm{U}}\right)$ by using $\mathrm{P}_{1}$ transducer $\left(\mathrm{P}_{\mathrm{U}}\right.$ is bigger than $\mathrm{P}_{\mathrm{D}}$, with the maximum pressure difference less than $200 \mathrm{psi}$ ).

5. Close the box to isolate PPAL to avoid the room temperature.

6. Set the temperature and leave it for at least 24 hours until the temperature in the whole system reaches the desired temperature.

7. Isolate all the sections in the PPAL by closing all the valves, and monitor the pressure over time to detect leakage in the system. Then repair or replace sections showing leakage and monitor the pressure again over time. Repeat this part until the system has no leakage.

8. Record upstream and downstream pressures, find their compressibility factor, and assure both UDPT's record a zero value then

9. Close Valves $V_{2}, V_{3}$, and $V_{5}$ to isolate the streams from the tanks to trap pressure at $\mathrm{UPTD}_{1}$.

10. Open $V_{1}$ to connect upstream and downstream, then wait for at least one minute until the system reaches equilibrium. At its equilibrium, the system's pressure is a value between $P_{D}$ and $\mathrm{P}_{\mathrm{U}}$. Therefore, $\mathrm{UPTD}_{1}$ reads a value greater than zero. Meanwhile, keep monitoring $\mathrm{UDPT}_{1}$ to make sure it does not exceed a maximum reading of $0.5 \mathrm{psi}$.

11. Turn the handle on the manual displacement pump until $\mathrm{UDPT}_{1}$ reads zero (That means that pressure in the whole system has reached to the initial upstream pressure, $\left.\mathrm{P}_{\mathrm{U}}\right)$.

12. Read the change of volume in the displacement pump $(\Delta \mathrm{V})$.

13. Equation 2-1 gives the volume of the section. 
This procedure can be repeated separately to find the volume of each section. The line volume test for each section has been repeated for different upstream and downstream pressures to validate the line volume measurements.

\subsubsection{Porosity Measurement Procedure:}

After the Apparatus Setup is done and the line volume is measured for each section, use the same apparatus setup for loading a sample and the same line volume procedure steps except the blank is replaced with the core plug, and using Equation 2-2 for porosity calculation in step 13.

\subsubsection{Permeability Measurement Procedure:}

When the Apparatus Setup is done, a core plug is set inside the core holder, and some confining pressure is applied. If no leakage exists, follow these steps (Refer to Figure 2):

1. Close valves $\mathrm{V}_{1}$ and $\mathrm{V}_{4}$ to separate upstream from downstream.

2. Open valves $\left(\mathrm{V}_{2}, \mathrm{~V}_{3}, \mathrm{~V}_{5}, \mathrm{~V}_{6}, \mathrm{~V}_{7}\right.$, and $\left.\mathrm{PV}\right)$ to charge downstream section $\left(\mathrm{V}_{1}\right.$ to $\mathrm{V}_{2}$ through $V_{6}$, called $\left.V_{D}\right)$ with $P_{D}$, and to charge upstream section $\left(V_{3}\right.$ to $V_{5}$, called $\left.V_{U}\right)$ with $P_{U}$.

3. Pressurize the entire system to the desired downstream pressure $\left(\mathrm{P}_{\mathrm{D}}\right)$ by using MDP (partial differential transducer). Then close the valve $\left(\mathrm{V}_{4}\right)$ between the two tanks.

4. Pressurize the upstream tank to the desired value $\left(\mathrm{P}_{\mathrm{U}}\right)$ by using $\mathrm{P}_{1}$ transducer $\left(\mathrm{P}_{\mathrm{U}}\right.$ is bigger than $\mathrm{P}_{\mathrm{D}}$, with the maximum pressure difference less than $200 \mathrm{psi}$ ).

5. Make sure both UDPT's read a zero value.

6. Close valve $\mathrm{V}_{6}$ to separate the upstream and the downstream of the core holder.

7. Set the software for pressure and time recording.

8. Close valve PV to allow the gas build up at downstream during the test.

9. Open valve $\mathrm{V}_{1}$ to let the gas flow through the sample (Test starts).

10. Record the number of the times that PV has been opened from the software panel. That is the number of times the test has been completed.

11. Stop the test when the measurement has repeated sufficiently,

12. Import the data from Lab view software system, analyze it and use Eq. 2-3 to calculate permeability. 


\section{Chapter 3}

\section{Objective and Methodology}

The objective of this study is to investigate the impact of pore and confining pressures on the porosity and the permeability of the Marcellus Shale and to evaluate the impact of adsorption/desorption on the permeability measurement results. The experiments performed on the Marcellus shale core plug (SW2) that was obtained from the vertical science well at the depth of 7547.03 feet. This science well was drilled at the Marcellus Shale Energy and Environment Laboratory (MSEEL) field site. MSEEL is collaborative research filed site developed to validate new knowledge and technology to improve recovery efficiency and minimize environmental implications of unconventional resource development. This chapter provides all the measurements on the core plug SW2 as follows:

\subsection{Line Volume Measurement}

Four-line volume sections of the PPAL are needed for porosity and permeability measurements. The volume of section $\mathrm{V}_{1}$ to $\mathrm{V}_{2}$ is required for porosity measurements and $\mathrm{V}_{6}$ to $\mathrm{PV}$ is needed for permeability measurements (See Figure 2). The volume of section $\mathrm{V}_{1}$ to $P V$ and $V_{1}$ to $V_{6}$ is needed for calculating the volume of section $V_{6}$ to $P V$. For each section, the experiment was repeated more than ten times while changing the upstream pressure and a pressure difference (MDP) to validate the results of line volume measurement. The results of the line volume measurements are provided in Appendix C.

\subsection{Permeability Measurements}

Table 2 illustrate a total of 54 runs that were performed with Helium and Nitrogen to evaluate:

1. Impact of the pore pressure on permeability (Runs 1-15).

2. Impact of the adsorption (Runs 6-15) on the permeability.

3. Impact of the stress on permeability and porosity (Run 16-26).

4. The fracture closure stress (Runs 27-54). 
Table 2: Permeability Measurements Plan

\begin{tabular}{|c|c|c|c|c|c|c|}
\hline $\begin{array}{l}\text { Run } \\
\text { No } \\
\end{array}$ & $\begin{array}{c}\text { Upstream } \\
\text { Pressure, } \\
\text { psia }\end{array}$ & $\begin{array}{c}\text { Downstream } \\
\text { Pressure, } \\
\text { psia } \\
\end{array}$ & $\begin{array}{c}\text { Average } \\
\text { Pressure, } \\
\text { psia } \\
\end{array}$ & $\begin{array}{c}\text { Confining } \\
\text { Pressure, } \\
\text { psia } \\
\end{array}$ & Gas & Application \\
\hline 1 & 300 & 100 & 200 & 4200 & \multirow{5}{*}{ He } & \multirow{5}{*}{ Slippage Effect } \\
\hline 2 & 400 & 200 & 300 & 4300 & & \\
\hline 3 & 500 & 300 & 400 & 4400 & & \\
\hline 4 & 600 & 400 & 500 & 4500 & & \\
\hline 5 & 700 & 500 & 600 & 4600 & & \\
\hline & & & & & & \\
\hline 6 & 300 & 100 & 200 & 4200 & \multirow{5}{*}{$\mathbf{N}_{2}$} & \multirow{5}{*}{$\begin{array}{l}\text { Slippage Effect } \\
\text { Adsorption Effect }\end{array}$} \\
\hline 7 & 400 & 200 & 300 & 4300 & & \\
\hline 8 & 500 & 300 & 400 & 4400 & & \\
\hline 9 & 600 & 400 & 500 & 4500 & & \\
\hline 10 & 700 & 500 & 600 & 4600 & & \\
\hline 11 & 700 & 500 & 600 & 4600 & \multirow{5}{*}{$\mathbf{N}_{2}$} & \multirow{5}{*}{ Desorption Effect } \\
\hline 12 & 600 & 400 & 500 & 4500 & & \\
\hline 13 & 500 & 300 & 400 & 4400 & & \\
\hline 14 & 400 & 200 & 300 & 4300 & & \\
\hline 15 & 300 & 100 & 200 & 4200 & & \\
\hline 16 & 400 & 200 & 300 & 1600 & \multirow{6}{*}{$\mathbf{N}_{2}$} & \multirow{6}{*}{$\begin{array}{c}\text { Increasing Stress } \\
\text { Effect }\end{array}$} \\
\hline 17 & 400 & 200 & 300 & 2700 & & \\
\hline 18 & 400 & 200 & 300 & 3400 & & \\
\hline 19 & 400 & 200 & 300 & 4300 & & \\
\hline 20 & 400 & 200 & 300 & 5300 & & \\
\hline 21 & 400 & 200 & 300 & 6200 & & \\
\hline & & & & & & \\
\hline 22 & 400 & 200 & 300 & 5300 & \multirow{5}{*}{$\mathbf{N}_{2}$} & \multirow{5}{*}{$\begin{array}{c}\text { Decreasing Stress } \\
\text { Effect }\end{array}$} \\
\hline 23 & 400 & 200 & 300 & 4300 & & \\
\hline 24 & 400 & 200 & 300 & 3400 & & \\
\hline 25 & 400 & 200 & 300 & 2700 & & \\
\hline 26 & 400 & 200 & 300 & 1600 & & \\
\hline
\end{tabular}




\begin{tabular}{|c|c|c|c|c|c|c|}
\hline $\begin{array}{l}\text { Run } \\
\text { No } \\
\end{array}$ & $\begin{array}{c}\text { Upstream } \\
\text { Pressure, } \\
\text { psia } \\
\end{array}$ & $\begin{array}{c}\text { Downstream } \\
\text { Pressure, } \\
\text { psia } \\
\end{array}$ & $\begin{array}{c}\text { Average } \\
\text { Pressure, } \\
\text { psia } \\
\end{array}$ & $\begin{array}{c}\text { Confining } \\
\text { Pressure, } \\
\text { psia } \\
\end{array}$ & Gas & Application \\
\hline 27 & 300 & 100 & 200 & 1500 & \multirow{4}{*}{$\mathbf{N}_{2}$} & \multirow{28}{*}{ 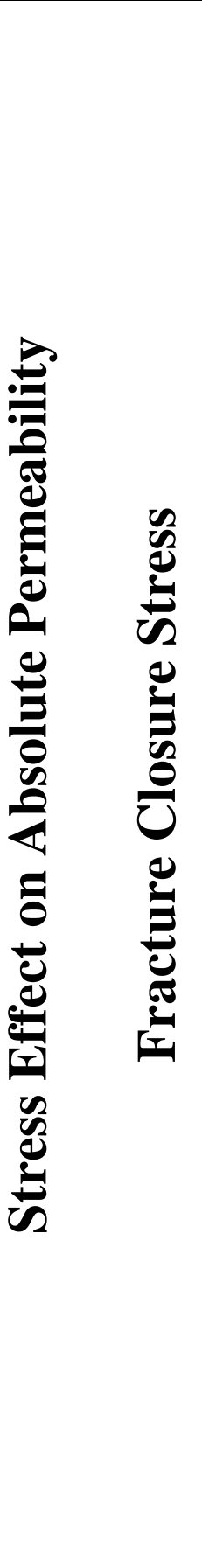 } \\
\hline 28 & 400 & 200 & 300 & 1600 & & \\
\hline 29 & 500 & 300 & 400 & 1700 & & \\
\hline 30 & 600 & 400 & 500 & 1800 & & \\
\hline 31 & 300 & 100 & 200 & 2600 & \multirow{8}{*}{$\mathbf{N}_{2}$} & \\
\hline 32 & 400 & 200 & 300 & 2700 & & \\
\hline 33 & 500 & 300 & 400 & 2800 & & \\
\hline 34 & 600 & 400 & 500 & 2900 & & \\
\hline 35 & 300 & 100 & 200 & 3300 & & \\
\hline 36 & 400 & 200 & 300 & 3400 & & \\
\hline 37 & 500 & 300 & 400 & 3500 & & \\
\hline 38 & 600 & 400 & 500 & 3600 & & \\
\hline 39 & 300 & 100 & 200 & 4200 & \multirow{4}{*}{$\mathbf{N}_{2}$} & \\
\hline 40 & 400 & 200 & 300 & 4300 & & \\
\hline 41 & 500 & 300 & 400 & 4400 & & \\
\hline 42 & 600 & 400 & 500 & 4500 & & \\
\hline 43 & 300 & 100 & 200 & 5200 & \multirow{4}{*}{$\mathbf{N}_{2}$} & \\
\hline 44 & 400 & 200 & 300 & 5300 & & \\
\hline 45 & 500 & 300 & 400 & 5400 & & \\
\hline 46 & 600 & 400 & 500 & 5500 & & \\
\hline 47 & 300 & 100 & 200 & 6100 & \multirow{4}{*}{$\mathbf{N}_{2}$} & \\
\hline 48 & 400 & 200 & 300 & 6200 & & \\
\hline 49 & 500 & 300 & 400 & 6300 & & \\
\hline 50 & 600 & 400 & 500 & 6400 & & \\
\hline 51 & 300 & 100 & 200 & 7200 & \multirow{4}{*}{$\mathbf{N}_{2}$} & \\
\hline 52 & 400 & 200 & 300 & 7300 & & \\
\hline 53 & 500 & 300 & 400 & 7400 & & \\
\hline 54 & 600 & 400 & 500 & 7500 & & \\
\hline
\end{tabular}


A run in this study refers to a single set of experimental conditions (average pressure, confining pressure, and temperature) of the experiment. Each run consists of many cycles. A cycle, in this study, refers to the period during which the pressure builds up in the downstream line until PV is opened and the pressure is released. The cycle can be repeated as many times as desired. The experimental results for each cycle can then be used to evaluate the permeability of the sample. For example, a Run with 50 cycles would suggests that the permeability measurement has been repeated 50 times for the same test conditions. The pressure buildup during each cycle is analyzed to assure that it changes linearly with time. The linear pressure builds up at $\mathrm{UDPT}_{2}$ indicates near steady state conditions which allows application of Darcy's law to calculate the permeability. The results are than subject to statistical analysis to validate the steady-state flow and are provided in Appendix D.

\subsection{Impact of the Pore Pressure on Permeability (Slippage Effect)}

A set of the permeability experiments consisted of 15 Runs with Helium (Run 1-5), Nitrogen adsorption (Run 6-10) and Nitrogen desorption (Run 11-15) were performed to determine the absolute permeability of the core plug, the measured permeability must be corrected for the slippage effect. The absolute permeability could be determined by changing the gas pressure under constant net stress conditions. The permeability measurements were performed at 5 different gas (pore) pressures while the net stress was maintained constant at 4000 psia. In other words, the difference between the confining pressure and the average gas pressure were kept constant during these experiments. The average gas pressures ranged from 200 psia to 600 psia, while the confining pressure ranged from 4200 to 4600 psia. Both Klinkenberg and double slippage corrections were applied to the results to evaluate the absolute permeability of the sample and to confirm the flow regime during the experiments. 


\subsection{Adsorption/Desorption Effect on Permeability}

The permeability experiments were repeated with Nitrogen by increasing the gas pressure (adsorption Runs 6-10) and by decreasing the gas pressure (desorption Runs 11-15). All the experiments were performed under constant net stress. It should be noted as the gas pressure is increased (or decreased), the gas can be adsorbed to (or desorbed from) the sample. Therefore, the flow rate during these experiment is monitored to establish constant flow rate (sample saturation with gas) at each gas pressure. The final stabilized flow rate is then used for evaluating the permeability. The results of flow rate monitoring are also provided in Appendix D. The absolute permeability can be determined by applying slippage correction. The absolute permeability were determined from the measurements with Nitrogen (both adsorption and desorption) and were compared against the absolute permeability value that were determined from the measurements with Helium. This would allow to evaluate the impact of adsorption/desorption on the permeability measurement results.

\subsection{Stress Effect on Permeability and Porosity}

To investigate the impact of stress, a set of porosity and permeability experiments under different net stresses were performed while the average gas pressure was maintained constant. The entire set of experiments consisted of 11 Runs with Nitrogen, with six different confining pressures increasing sequentially (Runs 16-21), and five more runs sequentially decreasing pressures (Runs 22-26). The confining pressure were increased from 1,600 psia to 6,200 psia, then decreased from 6,200 psia to 1,600 psia while the upstream (400 psia) and downstream (200 psia) gas pressures would be constant. 


\subsection{Fracture Closure Stress}

During this set of the experiments (Runs 26-54), the investigations were focused on developing a complete permeability-stress profile. The permeability of the core plug can be measured at 4 different average gas (pore) pressures ranging from 200 to 500 psia while maintaining the net stress on the sample constant. The measured permeability values at different pore pressures would be than utilized to determine the absolute permeability of the core plug by the application of the slippage method. Subsequently, the net stress on the sample would be increased by increasing the confining pressure. The permeability of the core plug can be then measured at different four average gas pressures while maintaining the net stress on the sample constant. The absolute permeability at new stress can be then determined. The net stress was increased in seven steps from 1,300 psia to 7,000 psia. As a result, a total of 28 permeability measurements (runs 27-54) were performed. Walsh's theorem was applied to the absolute permeability values at different net stress to determine the fracture closure pressure which is the point where the slope of the straight line changes. 


\section{Chapter 4}

\section{Result and Discussion}

\section{Overview}

This chapter provides the results of the experiments performed on the Marcellus Shale core plug (SW2) that was obtained from a vertical well drilled at the Marcellus Shale Energy and Environment Laboratory (MSEEL) at the depth of 7547.03 feet

\subsection{Permeability Measurements}

Appendix D shows the steady-state flow rate validation results which allows the application of Darcy's law to calculate the permeability. Figure 5 shows the results of the permeability measurements, where the confining pressure was 4,040 psia and the average gas pressure was 250 psia. However, this run took three hours and conducting 77 permeability tests (cycles).

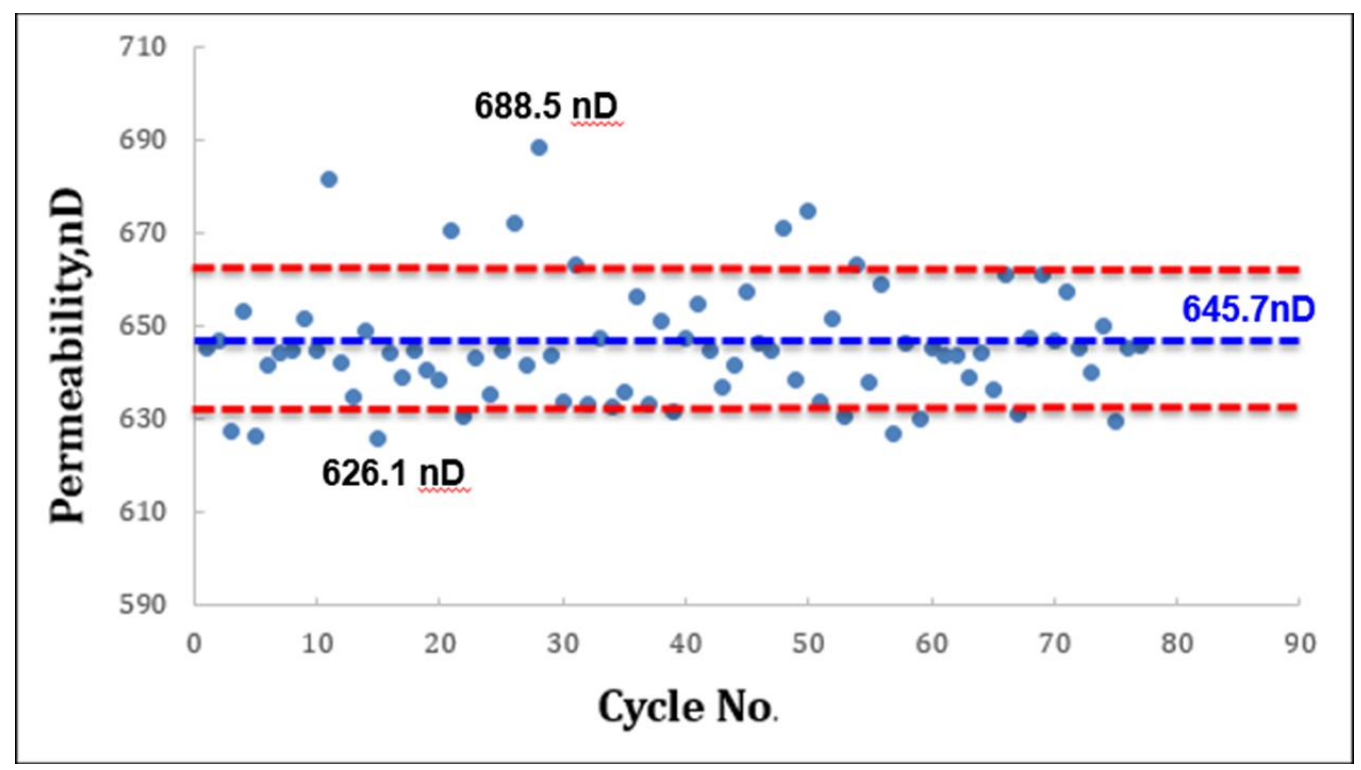

Figure 6: Permeability Measurement

Figure 5 shows that permeability values for those 77 cycles varied between 626.1 to 688.5 $\mathrm{nD}$. The $\mathrm{R}$ square test and statistical analysis were performed for the 77 cycles. Table 3, which, shows the mean value $645.7 \mathrm{nD}$, which is acceptable due to standard deviation. 
Table 3: Statistical analysis for Permeability Measurement

\begin{tabular}{|l|c|}
\hline \multicolumn{1}{|c|}{ Permeability } & nD \\
\hline Mean & 645.70 \\
\hline Standard Error & 1.45 \\
\hline Median & 644.74 \\
\hline Standard Deviation & 12.76 \\
\hline Sample Variance & 162.77 \\
\hline Kurtosis & 1.46 \\
\hline Skewness & 1.08 \\
\hline Range & 62.37 \\
\hline Minimum & 626.11 \\
\hline Maximum & 688.48 \\
\hline Sum & 49718.61 \\
\hline Count & 77.00 \\
\hline Confidence Level (95.0\%) & 2.90 \\
\hline
\end{tabular}

\subsection{Impact of the Pore Pressure on Permeability (Slippage Effect)}

The results (of Run 1-15) are shown in Table 4, Figure 7 and Figure 8 shows the result of gas pressure effect on permeability. It is clearly evident from this figure that lower pressures result in higher measured permeability values (more gas slippage). However, the absolute permeability is an intrinsic property reflecting the internal structure of the rock. That means permeability of the rock is a constant value no matter what pressure is used.

Table 4: The Measured Permeability Values at Different Gas Pressures (Slippage Effect)

\begin{tabular}{|c|c|c|c|c|c|}
\hline $\begin{array}{c}\text { Confining } \\
\text { pressure, psia }\end{array}$ & $\begin{array}{c}\text { Mean Gas } \\
\text { pressure, psia }\end{array}$ & $\begin{array}{c}\text { Net stress } \\
\text { pressure, psia }\end{array}$ & $\begin{array}{c}\text { Helium } \\
\text { Permeability (nD) }\end{array}$ & $\begin{array}{c}\mathrm{N}_{2} \text { Adsorption } \\
\text { Permeability (nD) }\end{array}$ & $\begin{array}{c}\mathrm{N}_{2} \text { Desorption } \\
\text { Permeability (nD) }\end{array}$ \\
\hline 4200 & 200 & 4000 & 478 & 468 & 451 \\
\hline 4300 & 300 & 4000 & 298 & 286 & 270 \\
\hline 4400 & 400 & 4000 & 223 & 211 & 205 \\
\hline 4500 & 500 & 4000 & 178 & 170 & 175 \\
\hline 4600 & 600 & 4000 & 152 & 141 & 141 \\
\hline
\end{tabular}




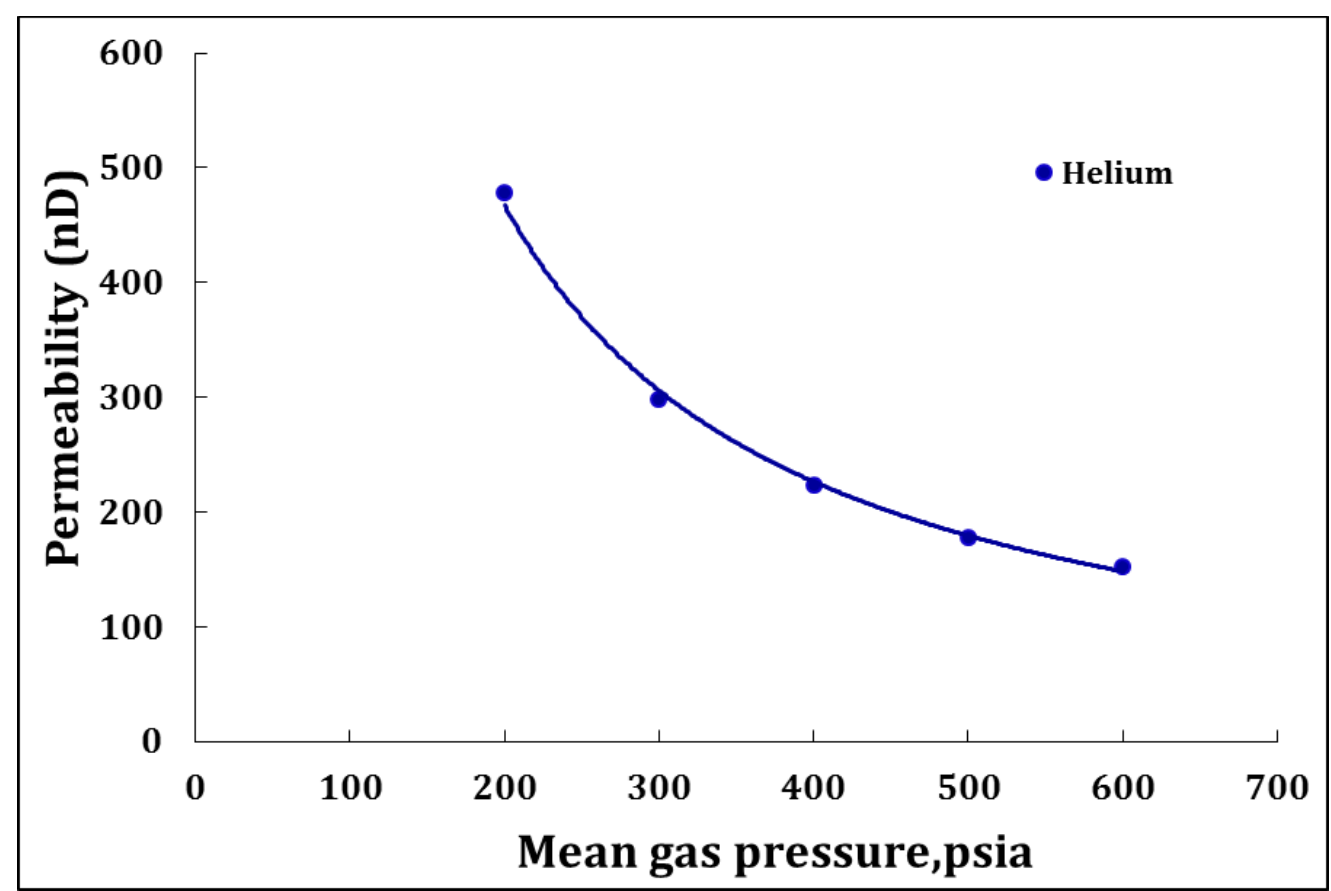

Figure 7: Gas pressure (slippage) effect on permeability using Helium

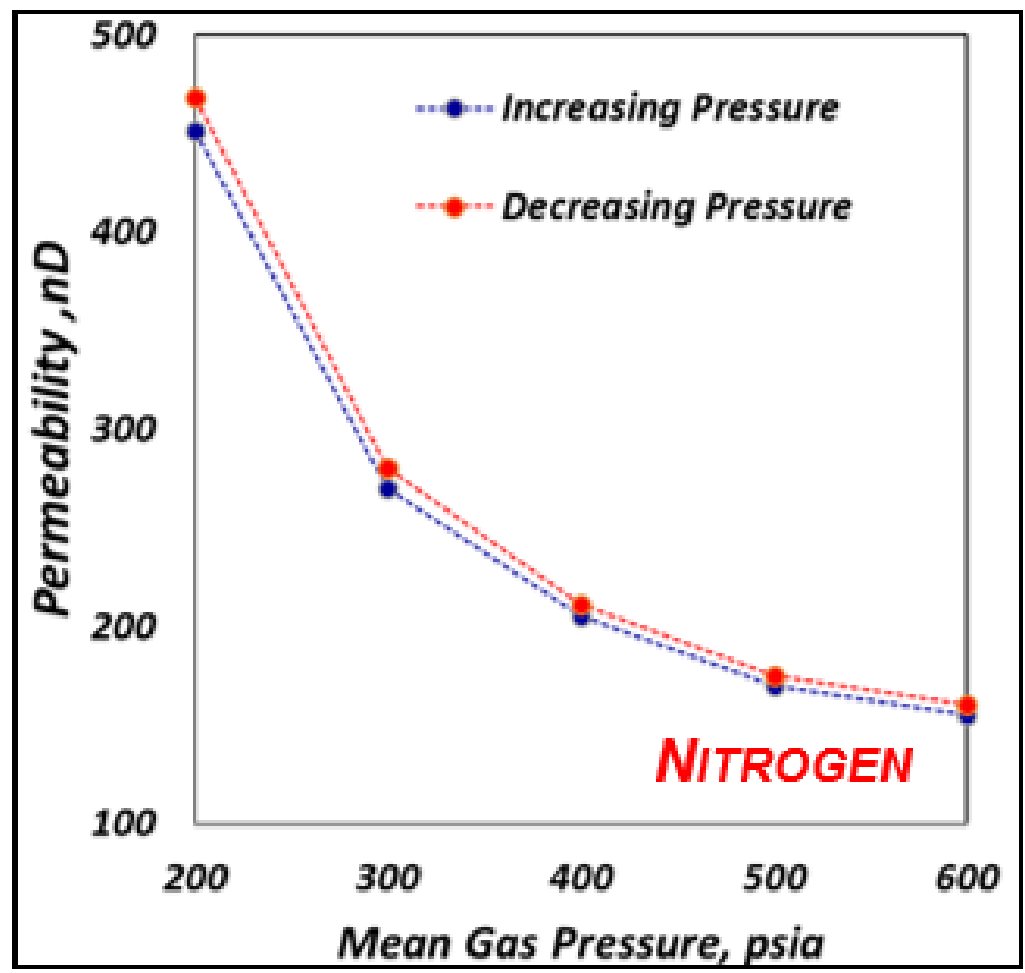

Figure 8: Gas pressure (slippage) effect on permeability using Nitrogen 


\subsection{Absolute Permeability Determination}

The application of Klinkenberg correction to the measured permeability values with Helium results in an absolute permeability value of $-18.955 \mathrm{nD}$ as presented in Figure 9. This value is, of course, not correct which suggest the flow regime is Transition flow due to small pores sizes. The double slippage correction as illustrated in Figure 10 results in a value of 124.27 $\mathrm{nD}$ for absolute permeability when using Helium which are consistent values.

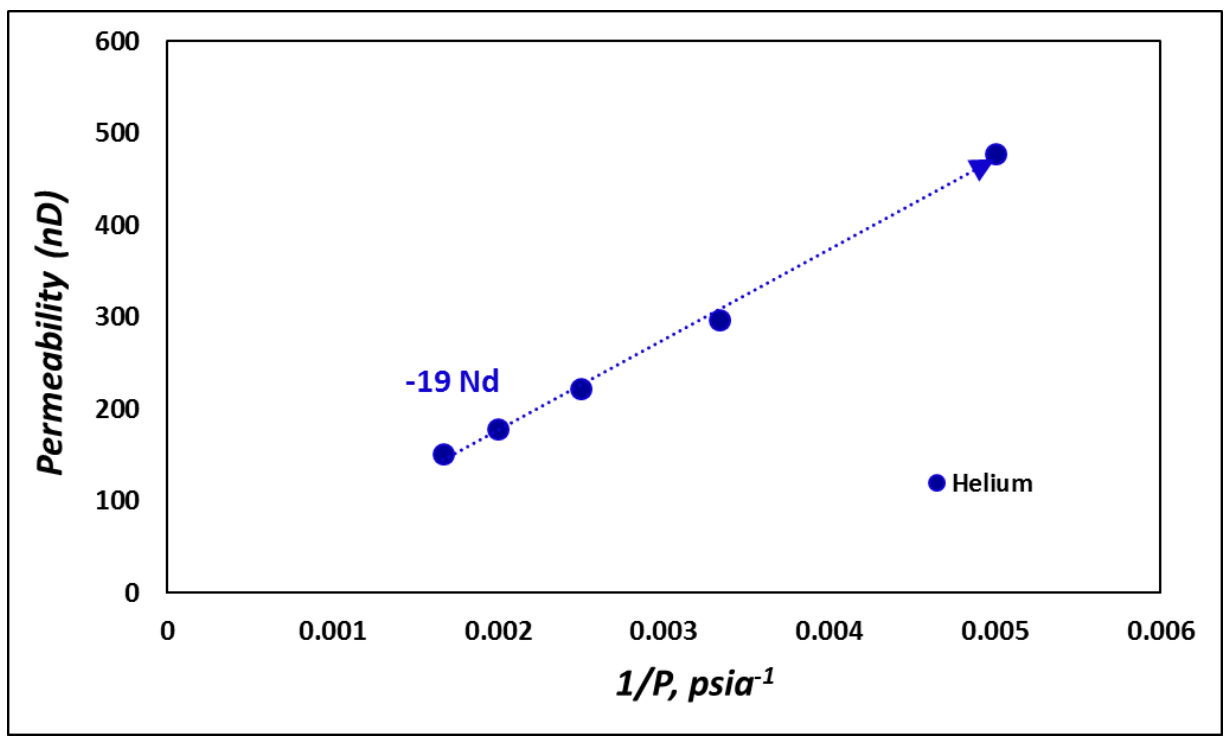

Figure 9: Klinkenberg correction on gas permeability measurements using Helium

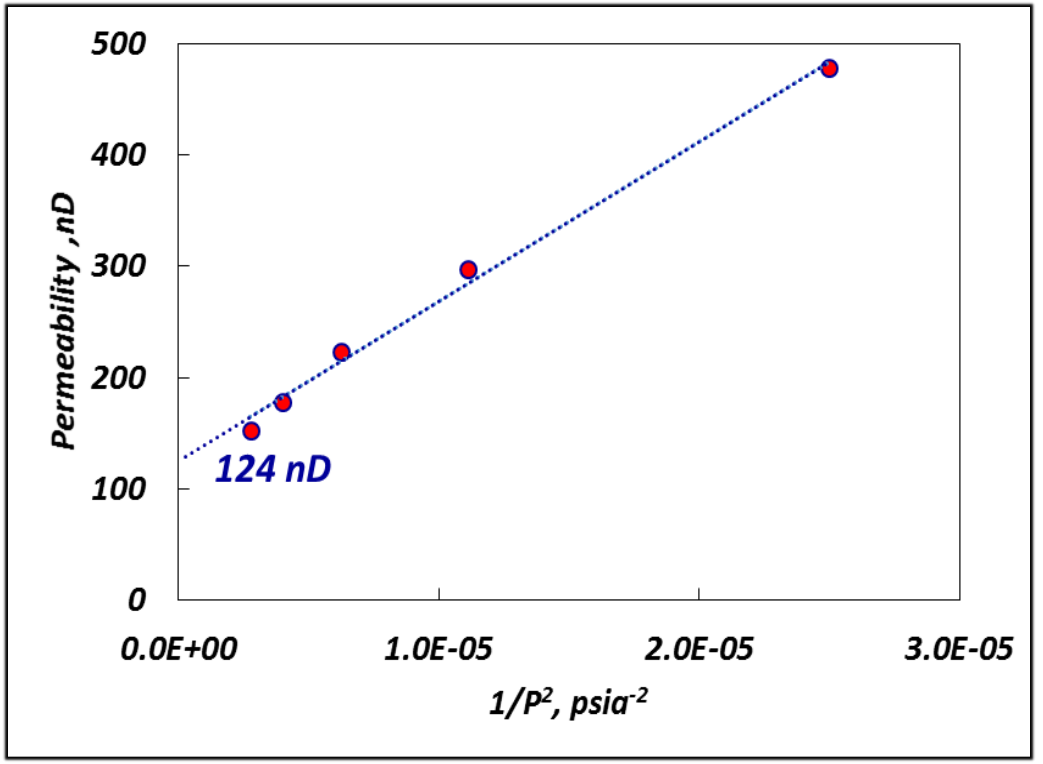

Figure 10: Double slippage correction on gas permeability using Helium 


\subsection{Adsorption/Desorption Effect on Permeability}

Nitrogen was used to measure adsorption and desorption effect on the permeability (Run 615). All the experiments were performed at constant net stress (4000 psia). Figure 11 shows absolute permeability values obtained by applying double slippage correction to permeability values measured with Nitrogen. The value of the absolute permeability measured by Nitrogen adsorption and Nitrogen desorption are same (114 nD) and smaller than value measured by Helium (124 nD) at the same net stress (4000 psia). This can be attributed to Nitrogen adsorption on the core plug which causes a reduction in pore diameters.

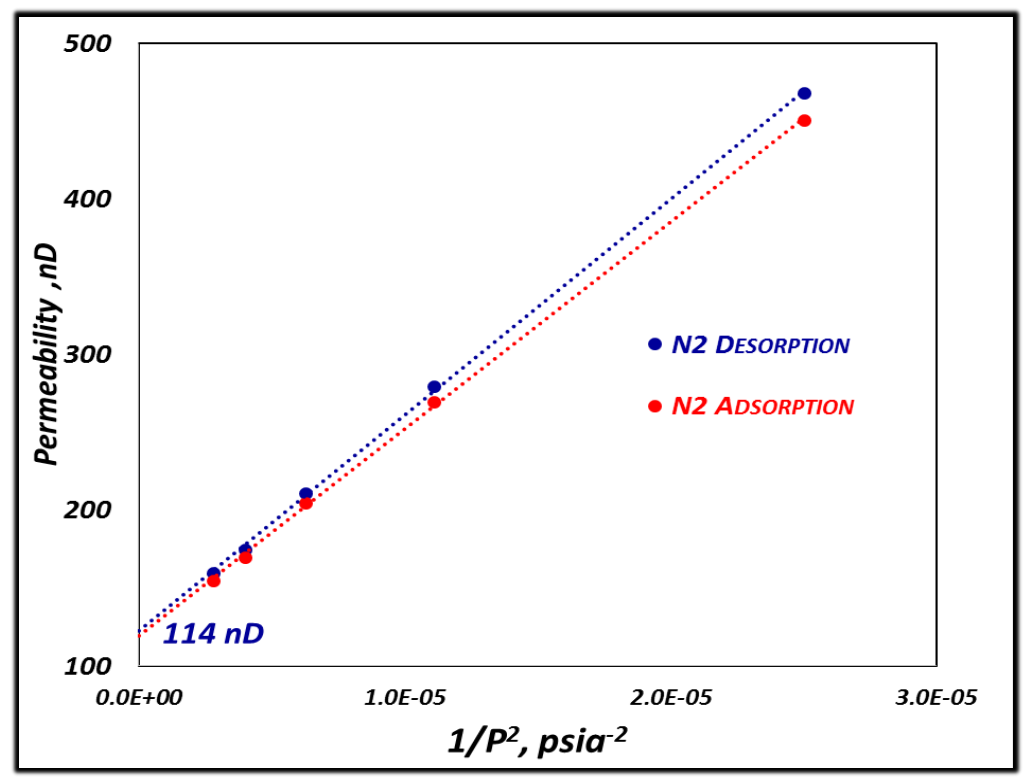

Figure 11: Adsorption/Desorption Effect on Permeability using Nitrogen

\subsection{Stress Effect on Permeability and Porosity}

Table 5 illustrate the results of Runs 16-26 that were performed to evaluate the effect of stress on permeability. Figure 12 indicates that as the confining pressure is increased from 1,600 psia to 6,200 psia in six steps (Runs 16-21), permeability has decreased dramatically. It can also be observed that the decline in the permeability is non-linear with the stress. On the other hand, as the confining pressure was decreased (Runs 22-26), the permeability increased. However, the permeability did not regain its initial value resulting in permeability hysteresis with stress. 
Table 5: Effect of stress on permeability and porosity

\begin{tabular}{|c|c|c|}
\hline \multicolumn{3}{|c|}{$\begin{array}{c}\text { Increasing Confining Pressure } \\
\text { Average pressure }=300 \text { psia }\end{array}$} \\
\hline Pressure, psia & Permeability,nD & Porosity $\%$ \\
\hline 1600 & 1720 & 2.2 \\
\hline 2700 & 1152 & 2.1 \\
\hline 3400 & 853 & 1.9 \\
\hline 4300 & 680 & 1.8 \\
\hline 5300 & 425 & 1.7 \\
\hline 6200 & 308 & 1.69 \\
\hline
\end{tabular}

\begin{tabular}{|c|c|c|}
\hline \multicolumn{3}{|c|}{$\begin{array}{c}\text { Decreasing Confining Pressure } \\
\text { Average pressure }=300 \text { psia }\end{array}$} \\
\hline Pressure, psia & Permeability, nD & Porosity \% \\
\hline 6200 & 308 & 1.69 \\
\hline 5300 & 249 & 1.7 \\
\hline 4300 & 313 & 1.8 \\
\hline 3400 & 447 & 1.9 \\
\hline 2700 & 657 & 2 \\
\hline 1600 & 1427 & 2.1 \\
\hline
\end{tabular}

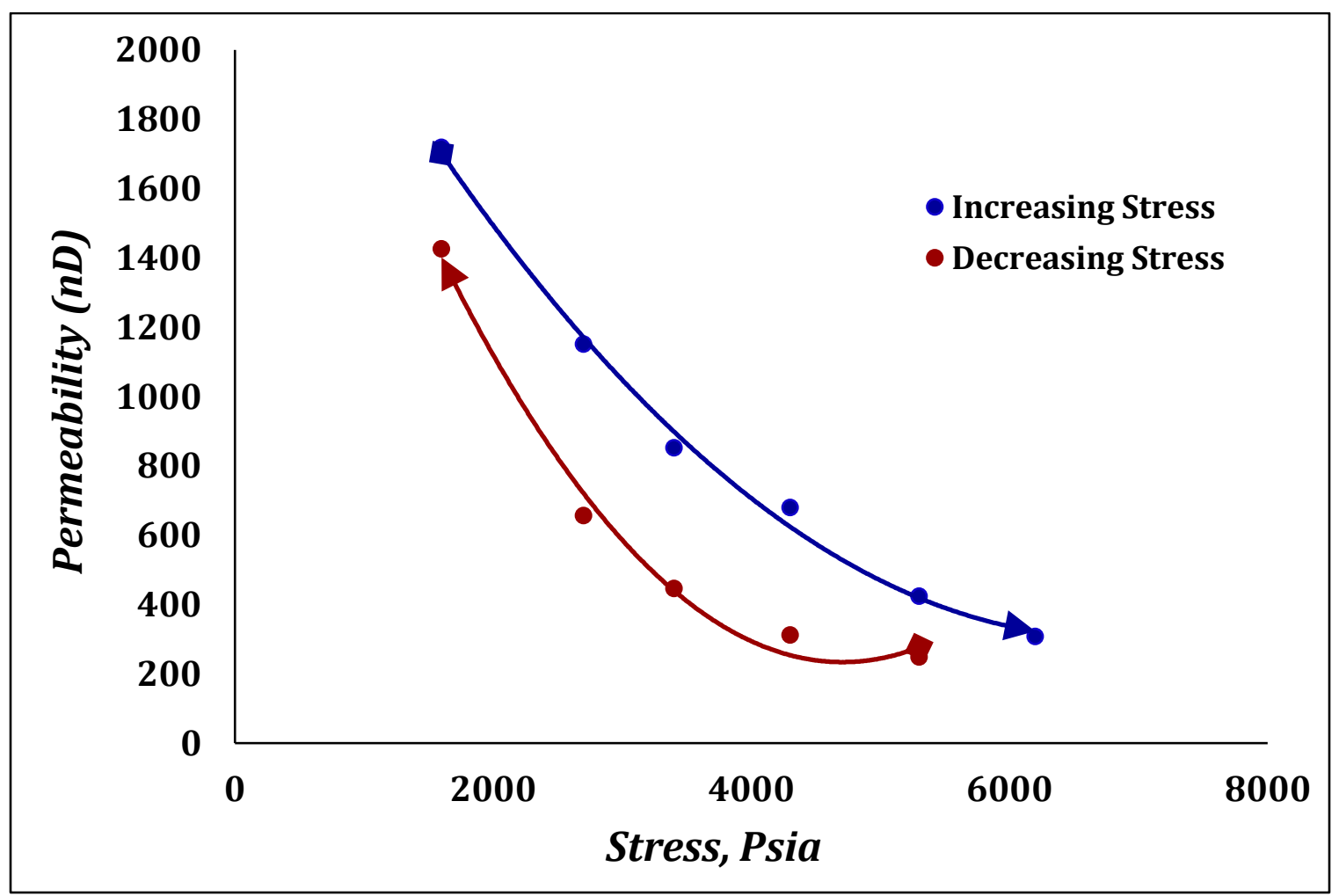

Figure 12: Stress Effect on Permeability

The porosity of the sample was simultaneously measured during the eleven aforementioned permeability measurement Runs (Runs 16-26) to evaluate the stress effect on the porosity. The results are illustrated in Figure 13. As it can be observed, the porosity varies with stress in a linear trend. The reduction in porosity is less severe than the permeability. Moreover, after decreasing the confining pressure from 6,200 psia to 1,600 psia, the porosity approximately regained its initial value and did not exhibit any hysteresis. 


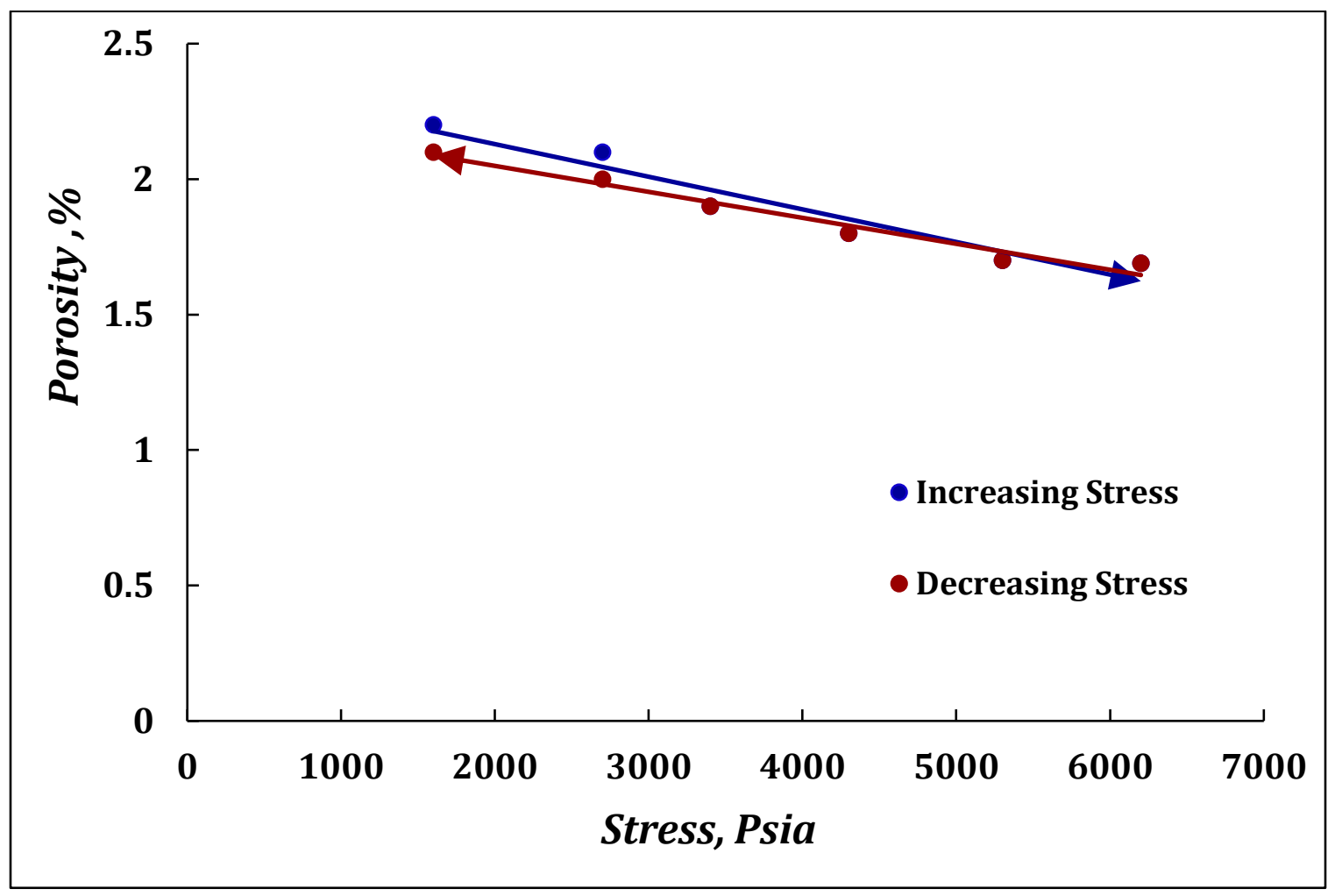

Figure 13: Stress effect on porosity

\subsection{Stress Effect on Absolute Permeability}

Table 6 illustrate the results of a complete profile of absolute permeability at a wide range of stresses was developed by performing 28 sets of experiments (Run 27-54) consisting of 4 different average gas pressures (ranging from 200 to 500 psia) and 7 different confining pressures (ranging from 1,300 to 7,000 psia). The absolute permeability was determined at each net stress by changing the gas pressure at four steps and applying double slippage correction to the results. Results of absolute permeability after double slippage correction are shown in Figure 14. Therefore, Figure 15 illustrates the relation between the absolute permeability and the net stress with using Nitrogen. As was observed previously, the relation is non-linear. 
Table 6: Stress Effect on Absolute Permeability

\begin{tabular}{|c|c|c|c|c|c|c|c|}
\hline $\begin{array}{l}\text { Run } \\
\text { No }\end{array}$ & $\begin{array}{c}\text { Upstream } \\
\text { Pressure, } \\
\text { psia }\end{array}$ & $\begin{array}{c}\text { Downstream } \\
\text { Pressure, } \\
\text { psia }\end{array}$ & $\begin{array}{l}\text { Average } \\
\text { Pressure, } \\
\text { psia }\end{array}$ & $\begin{array}{c}\text { Confining } \\
\text { Pressure, } \\
\text { psia }\end{array}$ & $\begin{array}{l}\text { Net stress } \\
\text { Pressure, } \\
\text { psia }\end{array}$ & $\begin{array}{c}\text { Measured } \\
\text { Permeability } \\
(\text { (nD) }\end{array}$ & $\begin{array}{c}\text { Absolute } \\
\text { Permeability } \\
\text { (nD) }\end{array}$ \\
\hline 27 & 300 & 100 & 200 & 1500 & 1300 & 2450 & \multirow{4}{*}{1031.8} \\
\hline 28 & 400 & 200 & 300 & 1600 & 1300 & 1720 & \\
\hline 29 & 500 & 300 & 400 & 1700 & 1300 & 1380 & \\
\hline 30 & 600 & 400 & 500 & 1800 & 1300 & 1237 & \\
\hline 31 & 300 & 100 & 200 & 2600 & 2400 & 1807 & \multirow{4}{*}{602.26} \\
\hline 32 & 400 & 200 & 300 & 2700 & 2400 & 1152 & \\
\hline 33 & 500 & 300 & 400 & 2800 & 2400 & 853 & \\
\hline 34 & 600 & 400 & 500 & 2900 & 2400 & 807 & \\
\hline 35 & 300 & 100 & 200 & 3300 & 3100 & 1307 & \multirow{4}{*}{437.25} \\
\hline 36 & 400 & 200 & 300 & 3400 & 3100 & 853 & \\
\hline 37 & 500 & 300 & 400 & 3500 & 3100 & 640 & \\
\hline 38 & 600 & 400 & 500 & 3600 & 3100 & 575 & \\
\hline 39 & 300 & 100 & 200 & 4200 & 4000 & 960 & \multirow{4}{*}{366.12} \\
\hline 40 & 400 & 200 & 300 & 4300 & 4000 & 680 & \\
\hline 41 & 500 & 300 & 400 & 4400 & 4000 & 512 & \\
\hline 42 & 600 & 400 & 500 & 4500 & 4000 & 440 & \\
\hline 43 & 300 & 100 & 200 & 5200 & 5000 & 615 & \multirow{4}{*}{243.03} \\
\hline 44 & 400 & 200 & 300 & 5300 & 5000 & 425 & \\
\hline 45 & 500 & 300 & 400 & 5400 & 5000 & 350 & \\
\hline 46 & 600 & 400 & 500 & 5500 & 5000 & 286 & \\
\hline 47 & 300 & 100 & 200 & 6100 & 5900 & 440 & \multirow{4}{*}{168.42} \\
\hline 48 & 400 & 200 & 300 & 6200 & 5900 & 308 & \\
\hline 49 & 500 & 300 & 400 & 6300 & 5900 & 240 & \\
\hline 50 & 600 & 400 & 500 & 6400 & 5900 & 192 & \\
\hline 51 & 300 & 100 & 200 & 7200 & 7000 & 281 & \multirow{4}{*}{87.02} \\
\hline 52 & 400 & 200 & 300 & 7300 & 7000 & 190 & \\
\hline 53 & 500 & 300 & 400 & 7400 & 7000 & 137 & \\
\hline 54 & 600 & 400 & 500 & 7500 & 7000 & 109 & \\
\hline
\end{tabular}




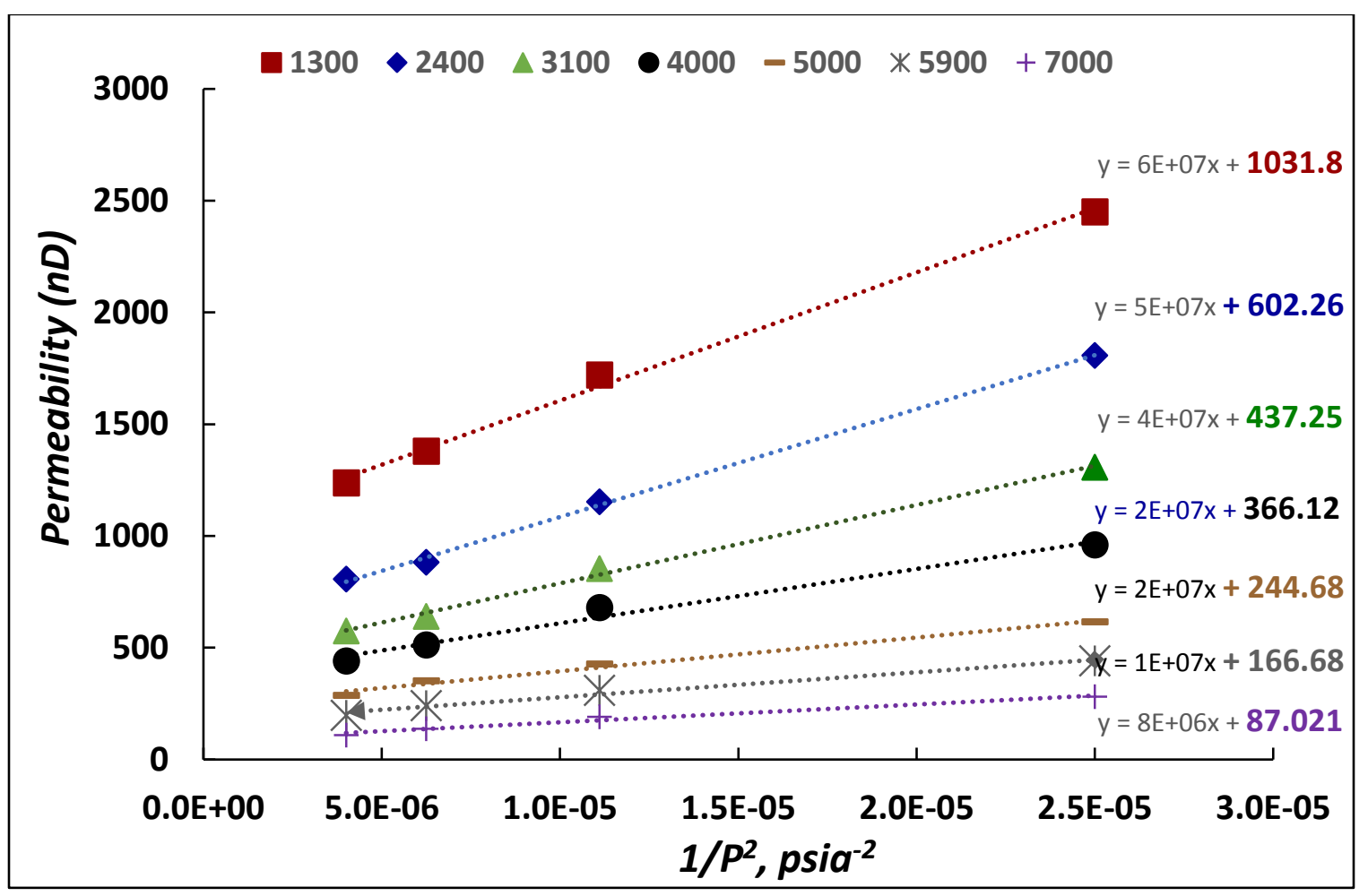

Figure 14: Absolute permeability by double slippage correction under stress condition

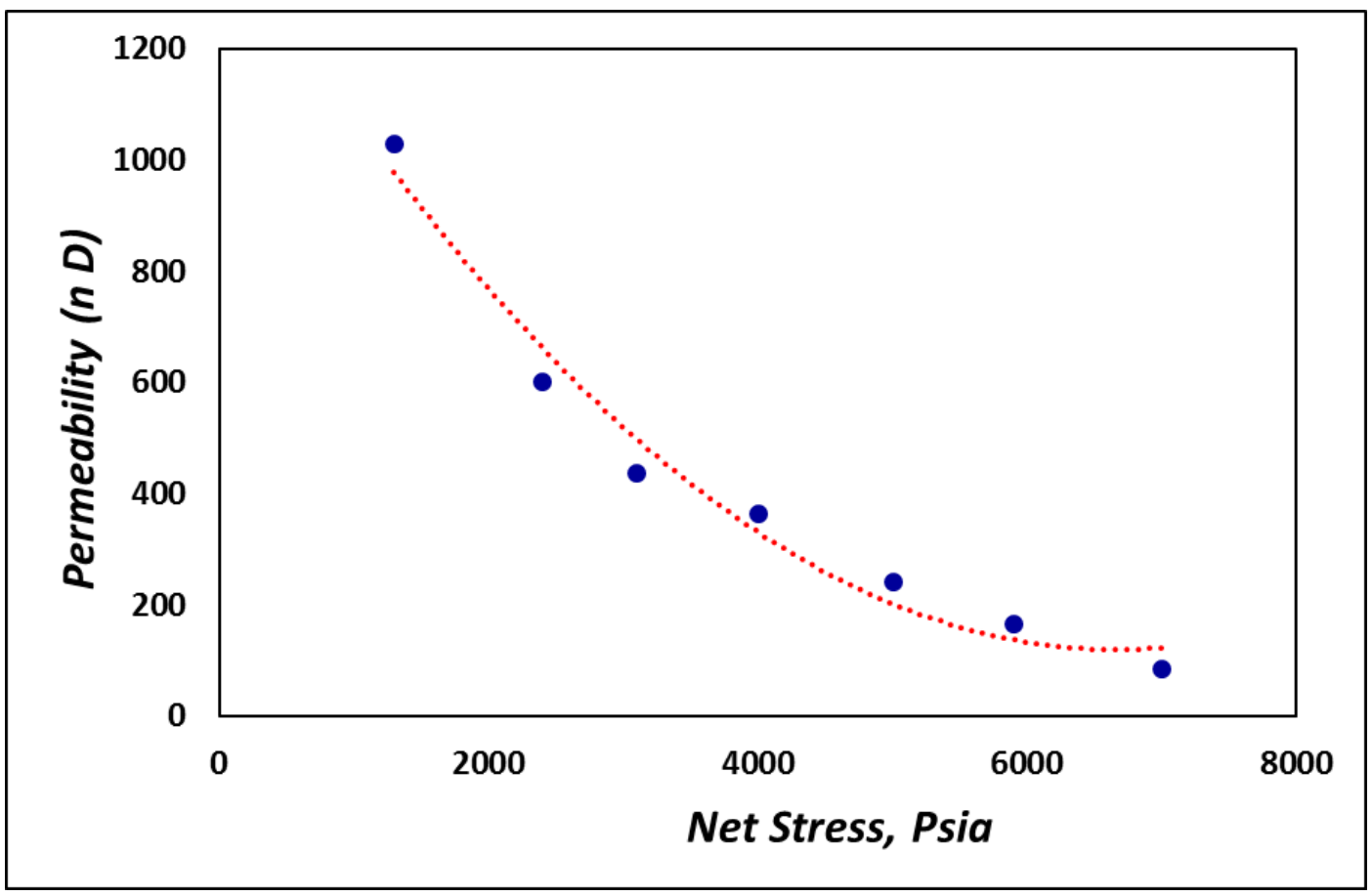

Figure 15: Stress effect on Absolute Permeability 


\subsection{Stress Induced Fractures}

The sample was relaxed for two weeks and a set of experiments (adsorption Runs 39-42) were performed at the same net stress $\left(4,000\right.$ psia) with using the same gas $\left(\mathrm{N}_{2}\right)$. The values of the absolute permeability before and after relaxation will then compared. Table 7 illustrates the measured permeability before (Run 6-10) and after relaxation (Run 39-42). Therefore, Figure 16 illustrates an absolute permeability of the sample (SW2) determinates by double slippage corrections after relaxation $(366.12 \mathrm{nD})$ is almost three times higher before relaxation $(113.67 \mathrm{nD})$. Therefore, it is clearly confirmed that fractures have been induced in the sample due to stress changes.

Table 7: Double slippage correction (N2 Desorption before and after relaxation)

\begin{tabular}{|c|c|c|}
\hline \multicolumn{3}{|c|}{ Net stress = 4000 psia } \\
\hline $\begin{array}{c}\text { Average Gas } \\
\text { Pressure, psia }\end{array}$ & $\begin{array}{c}\text { Permeability, nD } \\
\text { Before Relaxation }\end{array}$ & $\begin{array}{c}\text { Permeability, nD } \\
\text { After Relaxation }\end{array}$ \\
\hline 200 & 468 & 960 \\
\hline 300 & 286 & 680 \\
\hline 400 & 211 & 512 \\
\hline 500 & 170 & 440 \\
\hline
\end{tabular}

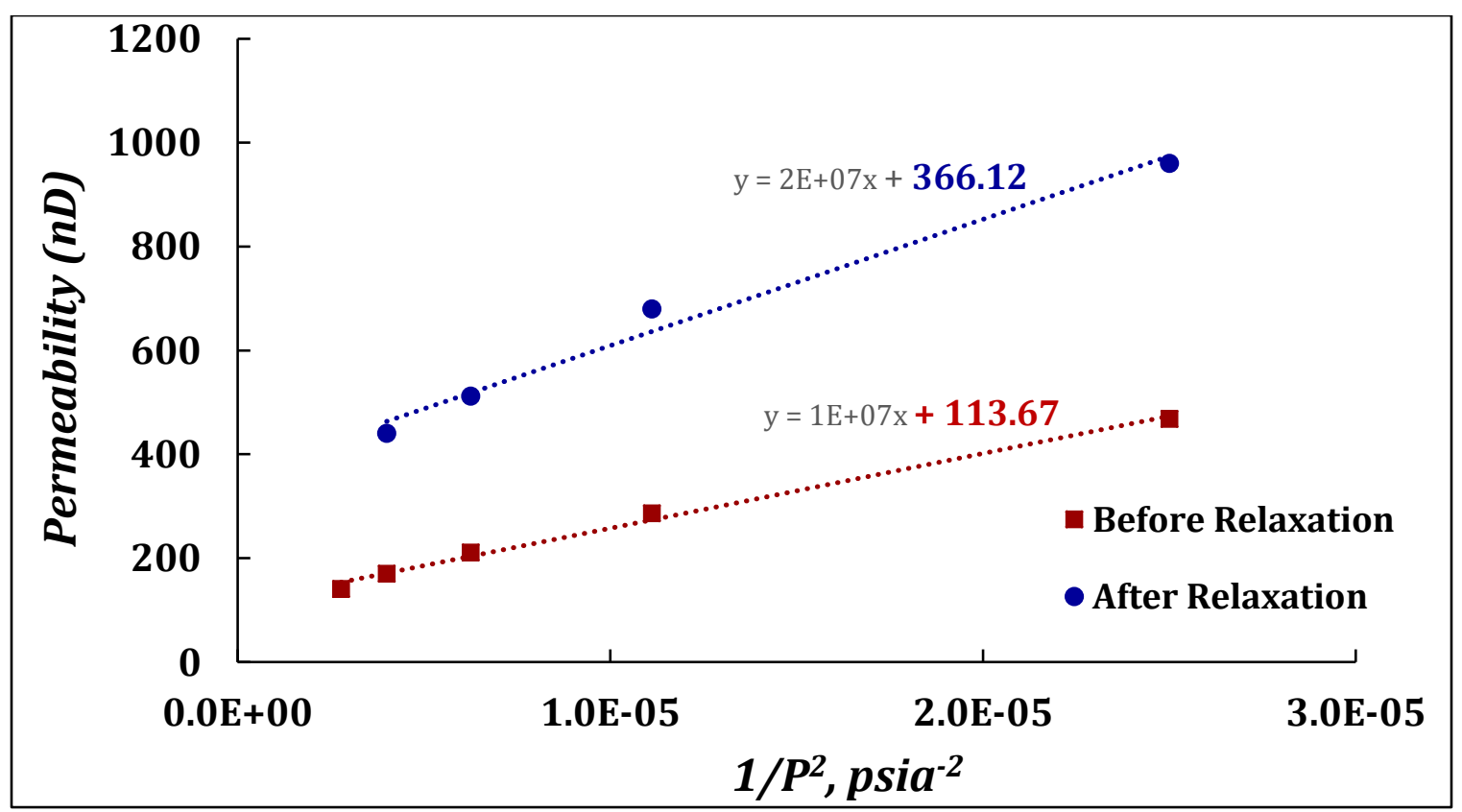

Figure 16: Double slippage correction $\left(\mathrm{N}_{2}\right.$ Desorption before and after relaxation) 


\subsection{Fracture Closure Pressure}

Walsh's theorem was applied to the measured absolute permeability values at different stress to determine the fracture closure pressure (Run 27-54). Figure 17 illustrate that the fracture closure pressure to be 4770 psi.

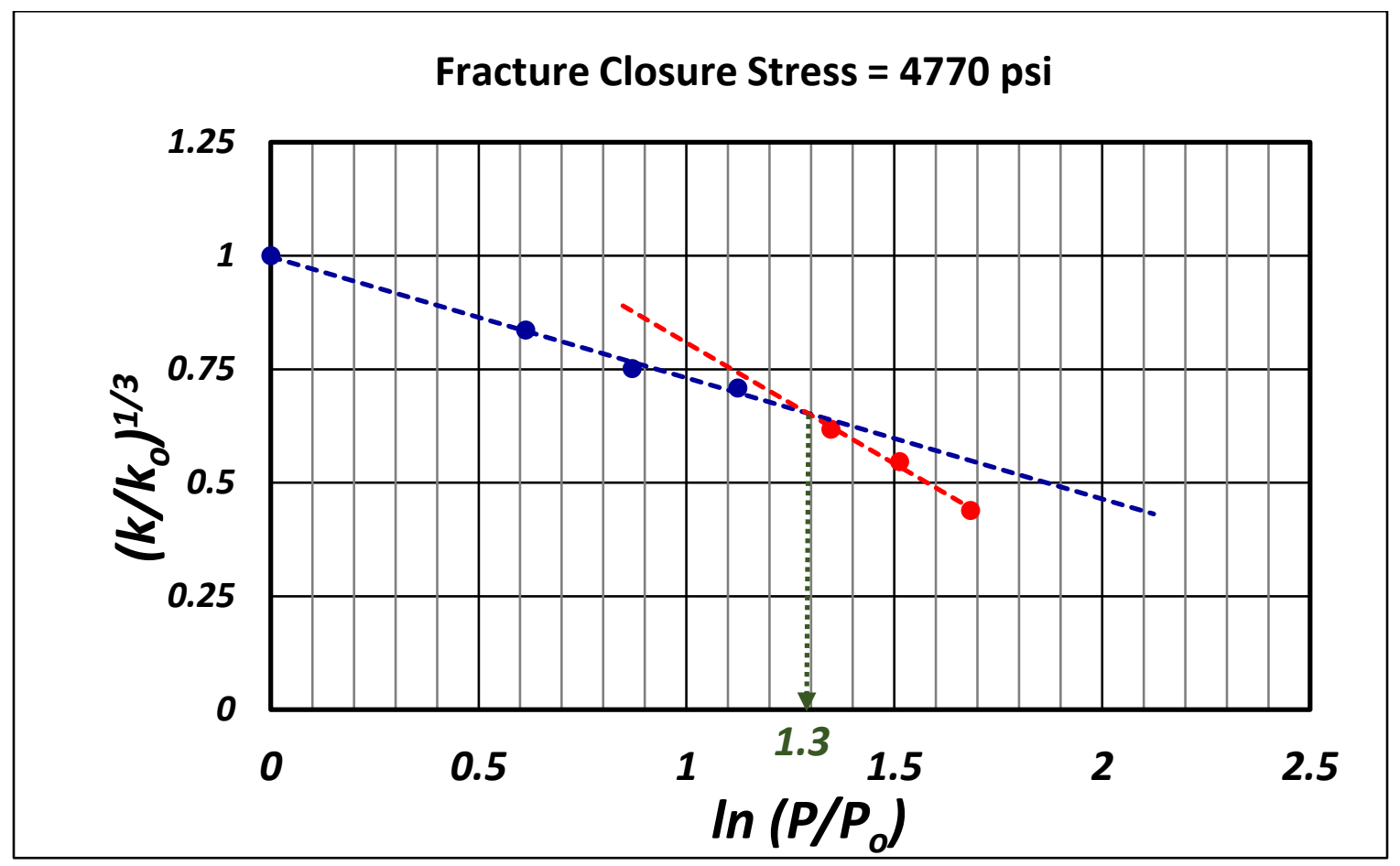

Figure 17: Fracture Closure Pressure 


\section{Chapter 5}

\section{Conclusions and Recommendation}

\subsection{Conclusions}

The following conclusion were reached during this study:

- The permeability and the porosity of the shale core plug can successfully be measured with PPAL.

- PPAL can provide fast, repeatable, and consistent results.

- Klinkenberg correction fails to provide reliable values for the absolute permeability of the shale sample.

- Double slippage correction provides accurate and reliable values for the absolute permeability which confirms that gas flow through shale is in transition flow regime.

- The permeability measurements with Helium were not impacted by adsorption effects.

- The permeability measurements with Nitrogen were impacted to a small degree by adsorption effects.

- The adsorption of gas to sample resulted in a reduction in the measured absolute permeability.

- Stress has a significant impact on shale permeability and resulting in hysteresis with increasing and decreasing stress values.

- The net stress has significant impact on the shale sample absolute permeability which exhibited a non-linear behavior with the stress.

- Stress has a minor impact on the shale porosity.

- The porosity exhibited a linear relation with stress because the fractures do not significantly contribute to the porosity.

- The porosity, after decreasing the stress, approximately regained its initial value and did not exhibit hysteresis withincreasing and decreasing stress. 


\subsection{Recommendation}

- It is recommended to monitor the pressure for at least 24 hours to assure that there is no leakage in the system.

- It is recommended to perform the stress tests at the later stages of experiments to minimize the damage to the samples.

- To add a heat jacket over the core holder to simulate the reservoir temperature.

- It is recommended to develop a software that can calculate the permeability and provide the various graphs in real-time for each experiment. 


\section{References}

1. Adesida, A. A. (2011). Characterization of Barnett Shale Kerogen Pore Size Distribution using DFT Analysis and Grand Canonical Monte Carlo Simulations. SPE Annual Technical Conference and Exhibition, 30 October-2 November, . Denver,Colorado.

2. Ambrose, R. H. (2010). New Pore-scale Considerations for Shale Gas in Place Calculations. SPE Unconventional Gas Conference. Pittsburgh, PA.

3. Ashish Mathur, Carl H. Sondergeld, and Chandra S. Rai., 2016. Comparison of Steady-State and Transient Methods for Measuring Shale Permeability. Paper SPE 180259 -MS presented at the SPE Low Perm Symposium held in Denver, Colorado, USA, 5-6 May 2016.

4. EIA. (2012). Retrieved from http://www.eia.gov/

5. Dalton, J. W. (2012). Technique Development to Measure Reservoir Properties in UNconventional Shale Core Samples. Master's Dissertation.

6. Daniel, J. Arthur, SPE, Brian Bohm, Bobbi Jo Coughlin, and Mark Layne, SPE, March 2009, Evaluation Implications of Hydraulic Fracturing in Shale Gas Reservoirs, Texas, USA, 2009 SPE Americans E\&P Environmental \& Safety Conference.

7. Darcy, H. (1856). Les Fontaines Publiques de la Ville de Dijon. Dalmont, Paris.

8. Du, C. Mike, Xu Zhang, Y. Zee Ma, Peter Kaufman, Brad Melton, and Sherif Gowelly, 2011, Integrated shale gas reservoir modeling, in Y. Z. Ma and P. R. La Pointe, eds., Uncertainty analysis and reservoir modeling: AAPG Memoir 96, p. 265-280. 
9. Fathi, E., Tinni, A., and Akkutlu, Y., 2012. Correction to Klinkenberg Slip Theory for Gas Dynamics in Nano-Capillaries. Intl. Journal of Coal Geol. 103, 51-59.

10. Holditch, Stephen A., Kent Perry, and John Lee. "Unconventional Gas Reservoirs-Tight Gas, Coal Seams, and Shales." National Petroleum Concil. (2007): Print.

11. Klinkenberg, L. (1941). The Permeability of Porous Media to Liquid and Gases. API Drilling and Production Practices, 200-213.

12. Schenk, Christopher J.: "Geologic Definition and Resource Assessment of Continuous (Unconventional) Gas Accumulations - the U.S. Experience," AAPG 66086 presented at the Ancient Oil-New Energy Conference, Cairo, October 27-30, 2002.

13. Soeder, Daniel J., March 1988. Porosity and Permeability Measurement of Eastern Devonian Gas Shale. SPE Formation Evaluation.

14. Tarek, A. (2010). Darcy's Law. In Reservoir Engineering Handbook (pp. 341-343). Oxford, UK: Gulf Professional Publishing.

15. Roy, S. R. (2003). Modeling gas flow through microchannels and nanopores. J. Appl. Phys. , 93, 4870-4879.

16. Rushing, J. N. (2004). Klinkenberg-Corrected Permeability Measurements in Tight Gas Sands: Steady-State versus Unsteady-State Techniques. Paper SPE 89867 presented at the SPE Annual Technical Conferene. Houston, Texas. 
17. Sondergeld, C.H., Newsahm, K.E., Comisky, J.T., Rice, M.C, and Rai, C.S., 2010. Petropysical Considerations in Evaluating and Producing Shale Gas Reservoirs. Paper SPE 131768 presented at the SPE Unconventional Gas Conference, Pittsburgh, Pennsylvania, 2325 February.

18. Tinni, A., Fathi, E., Agarwal, R., and Sondergeld, C., 2012. Shale Permeability Measurement on Plugs and Crushed Samples. Paper SPE 162235 presented at the Unconventional Resources Conference, Calgary, Alberta, 30 October- 1 November.

19. Walsh, J. (1981). Effect of Pore Pressure and Confining Pressure on Fracture Permeability. International Journal of Rock Mechanics and Mining Sciences \& Geomechanics, 429-435.

20. Walsh, J. B. (1984). The Effect of Pressure on Pand the Transport Properties of Rock. J. Geophys. Res. Solid Earth, 9425-9431.

21. Wu, Y. P. (1998). Gas Flow in Porous Media with Klinkenberg Effects. Transp. Porous Media , 32, 117-137.

22. Zamirian, M. (2015). New Experimental Approach to Measure Petrophysical Properties of Organic-Rich Shales. PHD Dissertation.

23. Zamirian, M., Aminian, K., Ameri, S., Fathi, E., 2014a. A New Steady State Experimental Technique for Shale Permeability Measurement. Paper SPE 171613-MS presented at the Unconventional Resources Conference, Calgary, Alberta, 30 September- 1 October.

24. Zamirian, M., Aminian, K., Ameri, S., Fathi, E., 2014b. A Fast and Robust Technique for Accurate Measurement of the Organic-rich Shales Characteristics under Steady-State Conditions. Paper SPE 171018-MS presented at the SPE Eastern Regional Meeting held in Charleston, West Virginia, USA, 21-23 October 2014. 
25. Zamirian, M., Aminian, K., Ameri, S., 2015a. Measurement of Key Shale Petrophysical Properties. Paper SPE 174968-MS presented at the SPE Annual Technical Conference and Exhibition held in Houston, Texas, USA, 28-30 September 2015. 


\section{Appendix A}

\section{Line Volume Measurement}

Line volume and porosity of samples are calculated based on the Boyle's law as it shown in a simpler diagram, Figure A-1

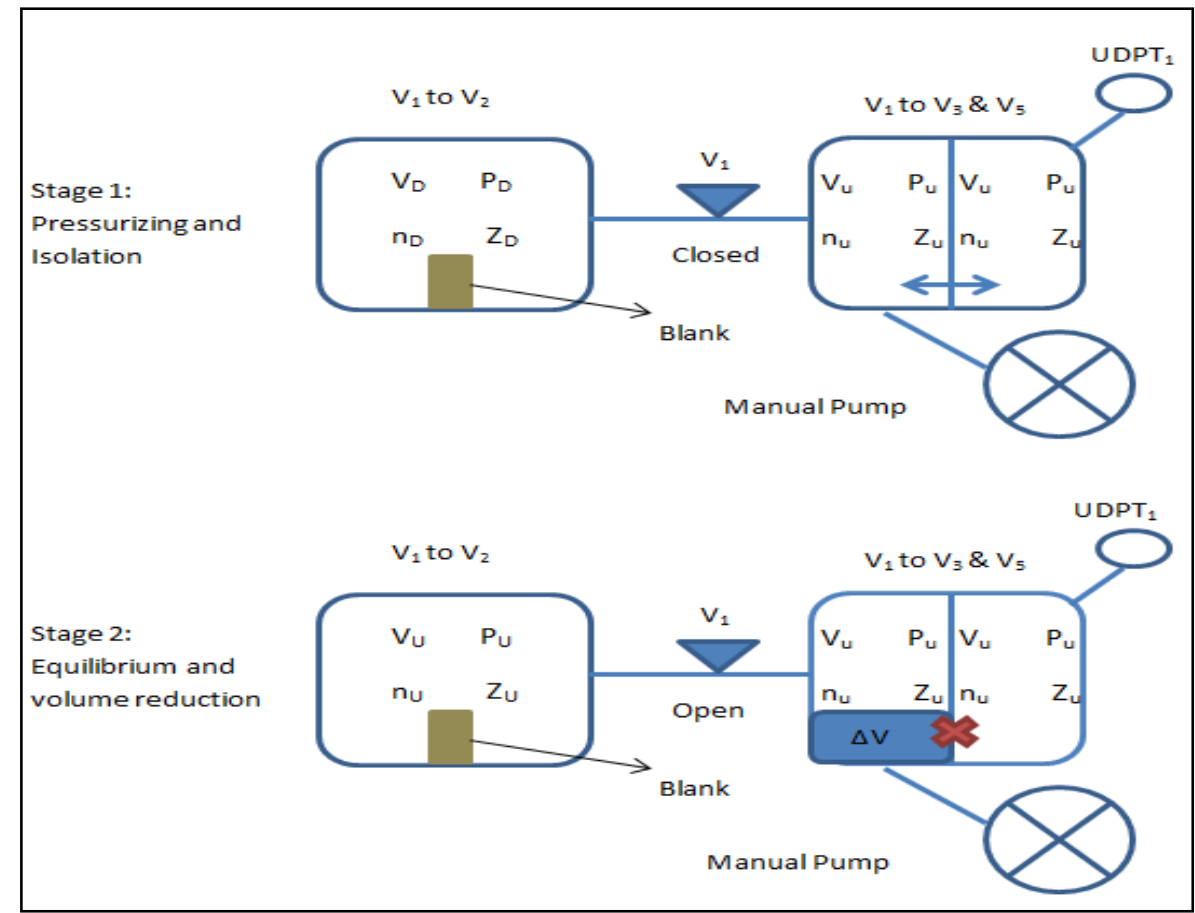

Figure A-1: Volume Measurement (Zamirian, 2015)

$\checkmark$ Section $V_{1}$ to $V_{2}$ through $V_{6}$, Called $V_{D}$ (downstream volume).

$\checkmark$ Section $\mathrm{V}_{3}$ to $\mathrm{V}_{5}$, Called $\mathrm{V}_{\mathrm{U}}$ (upstream volume).

$\checkmark \quad \Delta \mathrm{V}$ is the change of volume of the displacement pump.

\section{At stage one:}

The upstream and downstream sections have been pressurized and isolated. The equation of state for each upstream and downstream chamber can be written as follow where Equations A-1 and A-2 show it respectively.

$$
\frac{P_{U} V_{U}}{n_{U} Z_{U}}=R T
$$




$$
\frac{P_{D} V_{D}}{n_{D} Z_{D}}=R T
$$

Since the right side of Equations, A-1 and A-2 are equal, so the left side of both equations will be equal also, as Equation A-3:

$$
\frac{P_{U} V_{U}}{n_{U} Z_{U}}=\frac{P_{D} V_{D}}{n_{D} Z_{D}}
$$

Rearranging Equation A-3 in order to find the relation between upstream moles $\left(\mathrm{n}_{U}\right)$ and downstream $\left(\mathrm{n}_{\mathrm{D}}\right)$ moles:

$$
n_{D}=n_{U} \frac{P_{D} V_{D} Z_{U}}{P_{U} V_{U} Z_{D}}
$$

\section{At stage two:}

The upstream and downstream chambers are connected to each other to stabilize. Then, by reducing the volume in the upstream chamber, the pressure in connected chambers was brought back to the upstream pressure. The EOS for this situation is:

$$
\frac{P_{U}\left(V_{U}+V_{D}-\Delta V\right)}{\left(n_{U}+n_{D}\right) Z_{U}}=R T
$$

The right side of Equations A-1 and A-5 are equal; the left side of both equations will be equal, too as Equation A-6:

$$
\frac{P_{U}\left(V_{U}+V_{D}-\Delta V\right)}{\left(n_{U}+n_{D}\right) Z_{U}}=\frac{P_{U} V_{U}}{n_{U} Z_{U}}
$$

Replacing Equation A-4 on the left side of Equation A-6 to omit $n_{D}$ from the equation and simplifying it, would yield the downstream volume $\left(\mathrm{V}_{\mathrm{D}}\right)$ :

$$
V_{D}=\Delta V \frac{P_{U} Z_{D}}{P_{U} Z_{D}-P_{D} Z_{U}}
$$

\section{Where:}

$\mathrm{V}_{\mathrm{D}}$ : Volume of the line.

$\Delta \mathrm{V}$ : Volume of the gas displaced by the calibrated positive displacement manual pump.

$\mathrm{P}_{\mathrm{U}}$ The upstream pressure.

$\mathrm{P}_{\mathrm{D} \text { : }}$ The downstream pressure.

$\mathrm{Z}_{\mathrm{U}}$ : Upstream compressibility factor.

$\mathrm{Z}_{\mathrm{D}}$ : Downstream compressibility factor. 


\section{Appendix B}

\section{Permeability Measurement}

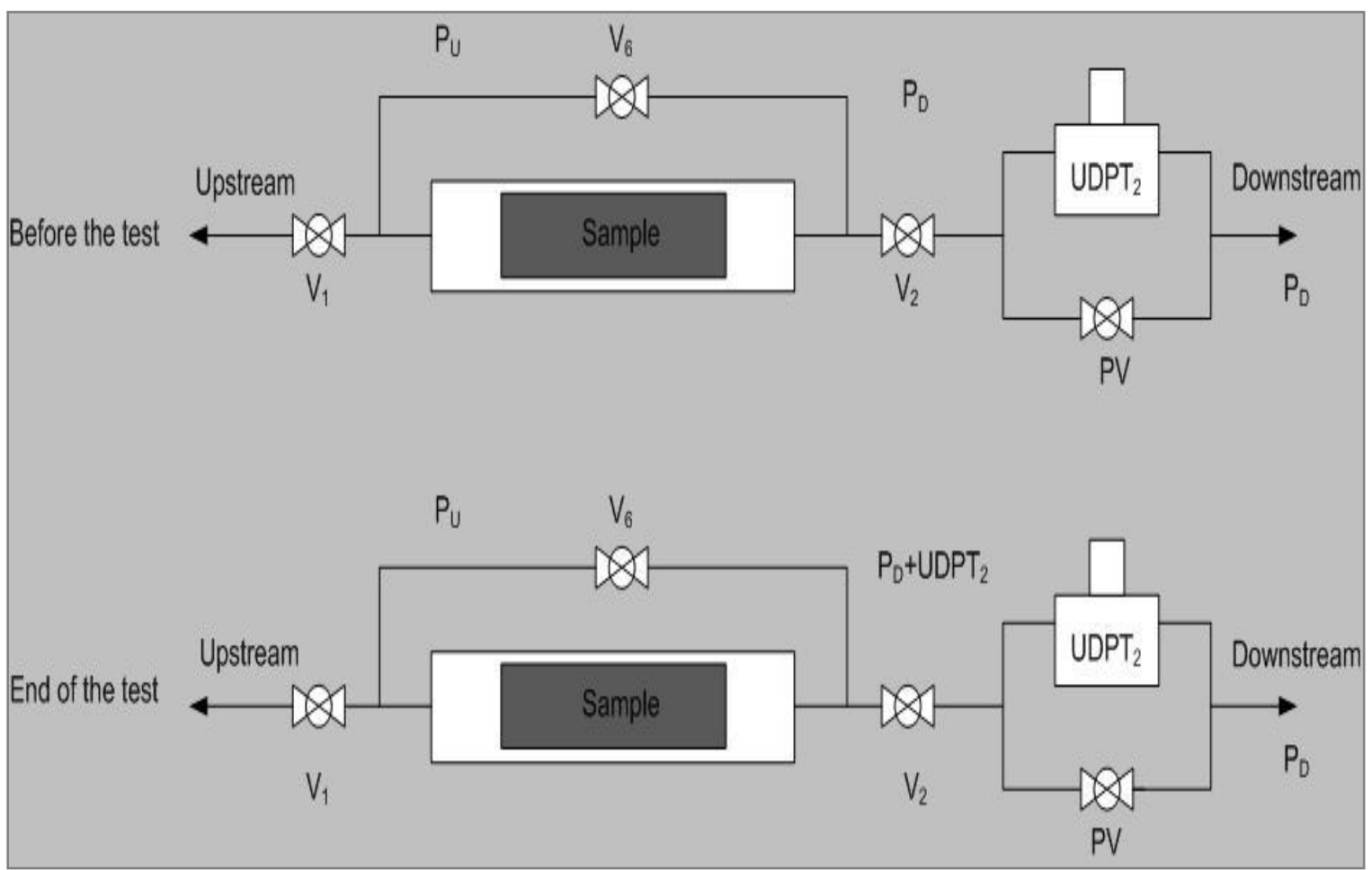

Figure B-1: Permeability Measurement (Zamirian, 2015)

To find the flow rate for the PPAL, the material balance equation has to be derived. Figure 5 illustrates the permeability measurement and calculation. Before starting the test, when upstream and downstream are isolated, the pressure after $V_{6}$ through the downstream tank is $\mathrm{P}_{\mathrm{D}}$. The volume of this section from $\mathrm{V}_{6}$ to $\mathrm{PV}$ known as $\mathrm{V}_{\mathrm{L}}$. The initial number of moles accumulated in the downstream using Equation of state (EOS) before gas flow can be explained by Equation B-1.

$$
n_{1}=\frac{P_{D} V_{L}}{Z_{D} R T}
$$

When the test begins, and $\mathrm{V}_{1}$ opens, gas flows through the sample and accumulates downstream, which increases the pressure and increases the $\mathrm{UDPT}_{2}$. $\mathrm{UDPT}_{2}$ shows the 
increment in $\mathrm{P}_{\mathrm{D}}$. The final pressure on downstream will not exceed 0.4 psi of the initial downstream pressure because the PV valve opens when $\mathrm{UDPT}_{2}$ reads its maximum value, 0.4 psi. Moreover, it can be assumed that the upstream and downstream compressibility factor (Z) is equal due to the similar conditions before and after the test, and this very small change in pressure ( $0.4 \mathrm{psi})$. However, the final mole number accumulated in downstream can be written as Equation B-2.

$$
n_{2}=\frac{\left(P_{D}+U D P T_{2}\right) V_{L}}{Z_{D} R T}=\frac{P_{D}+U D P T_{2}}{P_{D}} n_{1}
$$

Subtracting Equation B-1 from Equation B-2 gives the amount of gas that has passed through the sample during the test $(\Delta \mathrm{t})$. Equation B-3 shows the amount of gas that has flowed through the sample during the test.

$$
\Delta n=n_{2}-n_{1}=\frac{U D P T_{2} V_{L}}{Z_{n} R T}=\frac{U D P T_{2}}{P_{n}} n_{1}
$$

Calculating gas permeability using Darcy's law, the volume of flow rate has to be considered as the mean pressure and can be written at the end of the test as Equation B-4

$$
P_{m}=\frac{P_{U}+P_{D}+U D P T_{2}}{2}
$$

Writing the EOS for the amount of gas passed through the sample $(\Delta \mathrm{n})$ at a mean pressure would give the volume of gas passed through the sample:

$$
\Delta V_{m}=\frac{\Delta n Z_{m} R T}{P_{m}}
$$

Substituting Equations B-3 and B-4 in Equation B-5, simplifies it as:

$$
\Delta V_{m}=\frac{2 V_{L} Z_{m} U D P T_{2}}{Z_{D}\left(P_{U}+P_{D}+U D P T_{2}\right)}
$$

The maximum pressure difference (MDP) between upstream and downstream of PPAL has a maximum range of $200 \mathrm{psi}$. Thus, the pressure difference between downstream pressure and mean pressure would never exceed 100 psi. Therefore, is it a safe assumption that compressibility factors at mean pressure and downstream pressure can be considered to be equal which cancel each other in Equation B-6. 


$$
\Delta V_{m}=\frac{2 V_{L} U D P T_{2}}{\left(P_{U}+P_{D}+U D P T_{2}\right)}
$$

Darcy's law for gasses to calculate permeability is:

$$
k=\frac{q_{m} \mu L}{A\left(P_{U}-\left(P_{D}+U D P T_{2}\right)\right)}
$$

Replacing Equation B-7 into Equation B-8 yields:

$$
k=\frac{2 \mu L V_{L} U D P T_{2}}{A \Delta t\left(P_{U}^{2}-\left(P_{D}+U D P T_{2}\right)^{2}\right)}
$$

Where:

$k$ : Permeability, Darcy

$\mu$ : Viscosity, cp

$L$ : Length of the plug, $\mathrm{cm}$

$V_{L}:$ Line Volume ( $\mathrm{V}_{6}$ to $\left.\mathrm{PV}\right)$
$U D P T_{2}$ : Pressure builds up, atm $P_{D}$ : Down-stream absolute pressure, atm $P_{U}$ : Up-stream absolute pressure, atm $A$ : Cross section area of the plug, $\mathrm{cm}^{2}$

It should be noticed that in equation B-9, Line Volume is considered from V6 to PV valve, where gas accumulates in downstream. However, it should also be noted that the core sample has pore volume, which also accumulates downstream. In order to correct this, the pore volume of the sample would have to be added to the line volume. Therefore, Equation B-9 would be modified to Equation B-9 where $\mathrm{V}_{\mathrm{L}+\mathrm{P}}$ is the total volume of the downstream section plus the pore volume.

$$
k=\frac{2 \mu L V_{L+p} U D P T_{2}}{A \Delta t\left(P_{U}^{2}-\left(P_{D}+U D P T_{2}\right)^{2}\right)}
$$




\section{Appendix C}

\section{Line Volume Measurement Results}

Appendix C, shows the summary of data collected for the line volume measurement of each section ( $V_{1}$ to $P V, V_{1}$ to $V_{2}$ and $V_{1}$ to $V_{6}$ ). The gas used was Helium, and the confining pressure was 4000 psi. $\mathrm{P}_{\mathrm{U}}$ is the upstream pressure; $\mathrm{P}_{\mathrm{D}}$ is the downstream pressure and $\Delta \mathrm{P}$ is the difference between $P_{U}$ and $P_{D} . Z_{U}$ and $Z_{D}$ are the compressibility factors of the upstream and downstream respectively. Turn and division are the number of turns and divisions in the positive displacement pump. One turn is equal to $0.7142 \mathrm{~cm}^{3}$ and each turn has 25 divisions, which each division equaling to $0.028568 \mathrm{~cm}^{3}$. The $\Delta \mathrm{V}$ is the volume of the gas displaced by the positive displacement manual pump. $\mathrm{V}_{\mathrm{D}}$ is the volume of the line calculated by using Equation 2-1 as discussed in chapter two. 
Table C-1: Line volume measurement for section $V_{1}$ to $P V$

\begin{tabular}{|c|c|c|c|c|c|c|}
\hline No & \multicolumn{2}{|c|}{ Pressure, psi } & \multicolumn{2}{|c|}{ Compressibility factor (Z) } & \multicolumn{2}{|c|}{ Manual pump volume } \\
\hline \multirow[b]{4}{*}{1} & $\mathrm{P} 1$ & 201.50 & $T(F)$ & 79.80 & Turn & 7.00 \\
\hline & $\Delta \mathrm{P}$ & 50.30 & $\mathrm{Z1}$ & 1.00 & Division & 4.00 \\
\hline & $\mathrm{P} 2$ & 151.20 & $\mathrm{Z2}$ & 1.00 & $\Delta \mathrm{V}(\mathrm{cc})$ & 5.11 \\
\hline & \multicolumn{2}{|c|}{$\Delta \mathrm{P}$} & 50.30 & \multicolumn{2}{|c|}{$\operatorname{VD}(\mathrm{cc})$} & 20.49 \\
\hline \multirow[b]{4}{*}{2} & $\mathrm{P} 1$ & 210.50 & $T(F)$ & 80.20 & Turn & 7.00 \\
\hline & $\Delta \mathrm{P}$ & 53.20 & $\mathrm{Z1}$ & 1.00 & Division & 3.00 \\
\hline & $\mathrm{P} 2$ & 157.30 & $\mathrm{Z2}$ & 1.00 & $\Delta \mathrm{V}(\mathrm{cc})$ & 5.09 \\
\hline & \multicolumn{2}{|c|}{$\Delta \mathrm{P}$} & 53.20 & \multicolumn{2}{|c|}{$\operatorname{VD}(\mathrm{cc})$} & 20.12 \\
\hline \multirow[b]{4}{*}{3} & $\mathrm{P} 1$ & 220.30 & $T(F)$ & 79.70 & Turn & 6.00 \\
\hline & $\Delta \mathrm{P}$ & 51.20 & $\mathrm{Z1}$ & 1.00 & Division & 12.00 \\
\hline & $\mathrm{P} 2$ & 169.10 & $\mathrm{Z2}$ & 1.00 & $\Delta \mathrm{V}(\mathrm{cc})$ & 4.63 \\
\hline & \multicolumn{2}{|c|}{$\Delta P$} & 51.20 & \multicolumn{2}{|c|}{$\operatorname{VD}(\mathrm{cc})$} & 19.91 \\
\hline \multirow[b]{4}{*}{4} & P1 & 230.80 & $T(F)$ & 79.60 & Turn & 6.00 \\
\hline & $\Delta \mathrm{P}$ & 51.10 & $\mathrm{Z1}$ & 1.00 & Division & 5.00 \\
\hline & $\mathrm{P} 2$ & 179.70 & $\mathrm{Z2}$ & 1.00 & $\Delta \mathrm{V}(\mathrm{cc})$ & 4.43 \\
\hline & \multicolumn{2}{|c|}{$\Delta P$} & 51.10 & \multicolumn{2}{|c|}{$\operatorname{VD}(\mathrm{cc})$} & 20.00 \\
\hline \multirow[b]{4}{*}{5} & $\mathrm{P} 1$ & 240.60 & $T(F)$ & 79.50 & Turn & 6.00 \\
\hline & $\Delta \mathrm{P}$ & 52.30 & $\mathrm{Z1}$ & 1.00 & Division & 3.00 \\
\hline & $\mathrm{P} 2$ & 188.30 & $\mathrm{Z2}$ & 1.00 & $\Delta \mathrm{V}(\mathrm{cc})$ & 4.37 \\
\hline & \multicolumn{2}{|c|}{$\Delta \mathrm{P}$} & 52.30 & \multicolumn{2}{|c|}{$\operatorname{VD}(\mathrm{cc})$} & 20.11 \\
\hline \multirow[b]{4}{*}{6} & $\mathrm{P} 1$ & 250.70 & $T(F)$ & 80.10 & Turn & 7.00 \\
\hline & $\Delta \mathrm{P}$ & 62.20 & $\mathrm{Z1}$ & 1.00 & Division & 0.00 \\
\hline & $\mathrm{P} 2$ & 188.50 & $\mathrm{Z2}$ & 1.00 & $\Delta \mathrm{V}(\mathrm{cc})$ & 5.00 \\
\hline & \multicolumn{2}{|c|}{$\Delta \mathrm{P}$} & 62.20 & \multicolumn{2}{|c|}{ VD (cc) } & 20.15 \\
\hline \multirow[b]{4}{*}{7} & $\mathrm{P} 1$ & 261.00 & $T(F)$ & 80.00 & Turn & 6.00 \\
\hline & $\Delta \mathrm{P}$ & 61.40 & $\mathrm{Z1}$ & 1.00 & Division & 15.00 \\
\hline & $\mathrm{P} 2$ & 199.60 & $\mathrm{Z2}$ & 1.00 & $\Delta \mathrm{V}(\mathrm{cc})$ & 4.71 \\
\hline & \multicolumn{2}{|c|}{$\Delta \mathrm{P}$} & 61.40 & \multicolumn{2}{|c|}{$\operatorname{VD}(\mathrm{cc})$} & 20.04 \\
\hline \multirow[b]{4}{*}{8} & P1 & 273.00 & $T(F)$ & 79.60 & Turn & 7.00 \\
\hline & $\Delta \mathrm{P}$ & 71.70 & $\mathrm{Z1}$ & 1.00 & Division & 14.00 \\
\hline & $\mathrm{P} 2$ & 201.30 & $\mathrm{Z2}$ & 1.00 & $\Delta \mathrm{V}(\mathrm{cc})$ & 5.40 \\
\hline & & & 71.70 & & & 20.56 \\
\hline & $\mathrm{P} 1$ & 282.30 & $T(F)$ & 79.70 & Turn & 8.00 \\
\hline & $\Delta \mathrm{P}$ & 83.10 & $\mathrm{Z1}$ & 1.00 & Division & 10.00 \\
\hline & $\mathrm{P} 2$ & 199.20 & $\mathrm{Z2}$ & 1.00 & $\Delta \mathrm{V}(\mathrm{cc})$ & 6.00 \\
\hline 9 & & & 83.10 & & & 20.38 \\
\hline & $\mathrm{P} 1$ & 291.40 & $T(F)$ & 80.10 & Turn & 8.00 \\
\hline & $\Delta \mathrm{P}$ & 82.70 & $\mathrm{Z1}$ & 1.00 & Division & 0.00 \\
\hline & P2 & 208.70 & $\mathrm{Z2}$ & 1.00 & $\Delta \mathrm{V}(\mathrm{cc})$ & 5.71 \\
\hline 10 & & & 82.70 & & & 20.13 \\
\hline
\end{tabular}


Statistical analysis was done for the ten series of the line volume measurement for section V1 to PV tests to find a value for the final line volume. The results can be seen in Table C-2

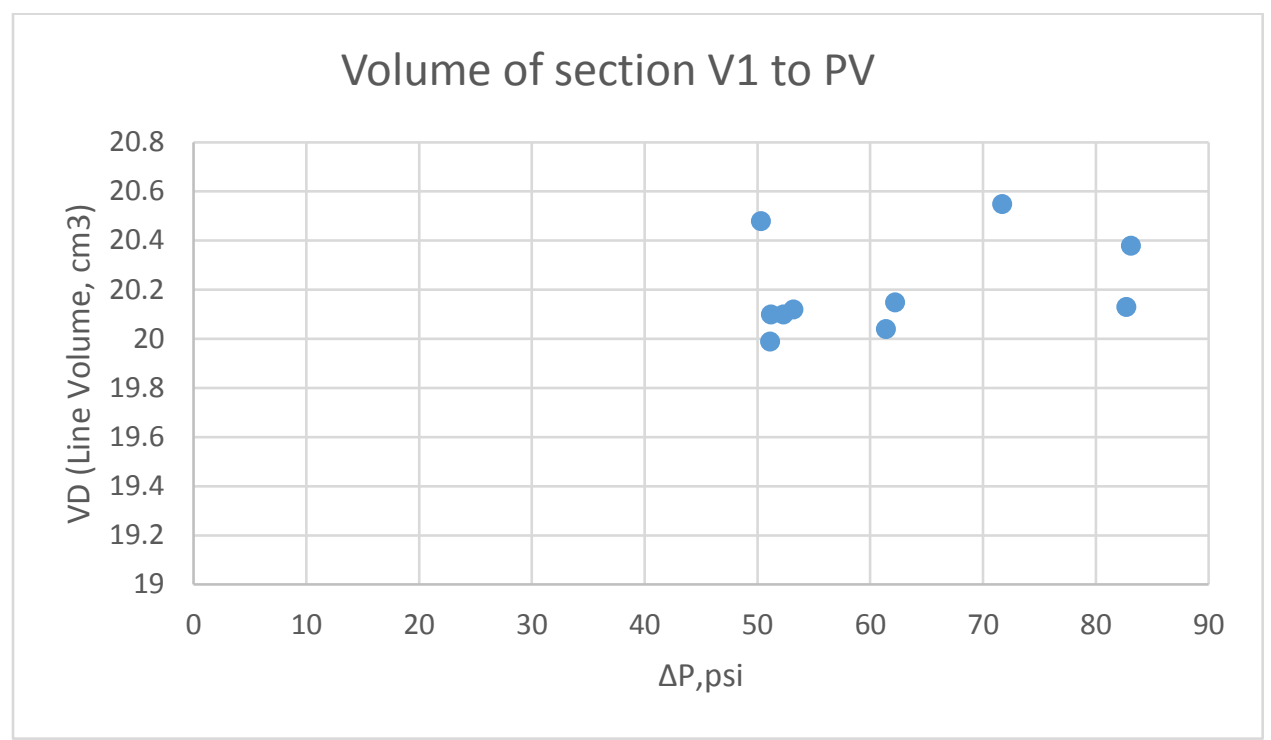

Figure C-1. Line Volume for Section V1 to PV

Table C-2: Statistical analysis for Section $\mathrm{V}_{1}$ to PV

\begin{tabular}{|l|l|}
\hline Value & $\mathbf{c m}^{\mathbf{3}}$ \\
\hline Mean & 20.20 \\
\hline Standard Error & 0.06 \\
\hline Median & 20.13 \\
\hline Mode & 20.10 \\
\hline Standard Deviation & 0.19 \\
\hline Range & 0.56 \\
\hline Minimum & 19.99 \\
\hline Maximum & 20.55 \\
\hline Sum & 202.04 \\
\hline Count & 10.00 \\
\hline Confidence Level (95.0\%) & 0.14 \\
\hline
\end{tabular}

Regarding Table C-2, the volume of section $\mathrm{V}_{1}$ to PV would be $20.2 \mathrm{~cm}^{3}$ with $0.19 \mathrm{~cm}^{3}$ of Standard Deviation. 
Table C-3: Line volume measurement for section $V_{1}$ to $V_{2}$

\begin{tabular}{|c|c|c|c|c|c|c|}
\hline NO & \multicolumn{2}{|c|}{ Pressure, psi } & \multicolumn{2}{|c|}{ Compressibility factor (Z) } & \multicolumn{2}{|c|}{ Manual pump volume } \\
\hline \multirow[b]{4}{*}{1} & $\mathrm{P} 1$ & 121.40 & $T(F)$ & 79.80 & Turn & 3.00 \\
\hline & $\Delta \mathrm{P}$ & 50.30 & $\mathrm{Z1}$ & 1.00 & Division & 6.00 \\
\hline & $\mathrm{P} 2$ & 71.10 & $\mathrm{Z2}$ & 1.00 & $\Delta \mathrm{V}(\mathrm{cc})$ & 2.31 \\
\hline & \multicolumn{2}{|c|}{$\Delta \mathrm{P}$} & 50.30 & \multicolumn{2}{|c|}{$\operatorname{VD}(c c)$} & 5.58 \\
\hline \multirow[b]{4}{*}{2} & $\mathrm{P} 1$ & 121.10 & $T(F)$ & 79.80 & Turn & 3.00 \\
\hline & $\Delta \mathrm{P}$ & 50.20 & $\mathrm{Z1}$ & 1.00 & Division & 5.50 \\
\hline & P2 & 70.90 & $\mathrm{Z2}$ & 1.00 & $\Delta \mathrm{V}(\mathrm{cc})$ & 2.30 \\
\hline & \multicolumn{2}{|c|}{$\Delta P$} & 50.20 & \multicolumn{2}{|c|}{$\operatorname{VD}(c c)$} & 5.55 \\
\hline \multirow[b]{4}{*}{3} & P1 & 201.20 & $T(F)$ & 79.90 & Turn & 3.00 \\
\hline & $\Delta \mathrm{P}$ & 103.40 & Z1 & 1.00 & Division & 24.00 \\
\hline & P2 & 97.80 & $\mathrm{Z2}$ & 1.00 & $\Delta \mathrm{V}(\mathrm{cc})$ & 2.83 \\
\hline & \multicolumn{2}{|c|}{$\Delta \mathrm{P}$} & 103.40 & \multicolumn{2}{|c|}{$\mathrm{VD}(\mathrm{cc})$} & 5.50 \\
\hline \multirow[b]{4}{*}{4} & P1 & 200.80 & $T(F)$ & 80.00 & Turn & 3.00 \\
\hline & $\Delta \mathrm{P}$ & 102.90 & $\mathrm{Z1}$ & 1.00 & Division & 24.50 \\
\hline & $\mathrm{P} 2$ & 97.90 & $\mathrm{Z2}$ & 1.00 & $\Delta \mathrm{V}(\mathrm{cc})$ & 2.84 \\
\hline & \multicolumn{2}{|c|}{$\Delta \mathrm{P}$} & 102.90 & \multicolumn{2}{|c|}{$\mathrm{VD}(\mathrm{cc})$} & 5.55 \\
\hline \multirow[b]{4}{*}{5} & $\mathrm{P} 1$ & 303.40 & $\mathrm{~T}(\mathrm{~F})$ & 79.80 & Turn & 5.00 \\
\hline & $\Delta \mathrm{P}$ & 198.20 & $\mathrm{Z1}$ & 1.00 & Division & 0.00 \\
\hline & $\mathrm{P} 2$ & 105.20 & $\mathrm{Z2}$ & 1.00 & $\Delta \mathrm{V}(\mathrm{cc})$ & 3.57 \\
\hline & \multicolumn{2}{|c|}{$\Delta \mathrm{P}$} & 198.20 & \multicolumn{2}{|c|}{ VD (cc) } & 5.47 \\
\hline \multirow[b]{4}{*}{6} & $\mathrm{P} 1$ & 303.20 & $T(F)$ & 79.70 & Turn & 5.00 \\
\hline & $\Delta \mathrm{P}$ & 198.10 & $\mathrm{Z1}$ & 1.00 & Division & 1.00 \\
\hline & $\mathrm{P} 2$ & 105.10 & $\mathrm{Z2}$ & 1.00 & $\Delta \mathrm{V}(\mathrm{cc})$ & 3.60 \\
\hline & \multicolumn{2}{|c|}{$\Delta \mathrm{P}$} & 198.10 & \multicolumn{2}{|c|}{$\mathrm{VD}(\mathrm{cc})$} & 5.51 \\
\hline \multirow[b]{4}{*}{7} & $\mathrm{P} 1$ & 301.20 & $T(F)$ & 79.90 & Turn & 2.00 \\
\hline & $\Delta \mathrm{P}$ & 104.30 & $\mathrm{Z1}$ & 1.00 & Division & 17.00 \\
\hline & $\mathrm{P} 2$ & 196.90 & $\mathrm{Z2}$ & 1.00 & $\Delta \mathrm{V}(\mathrm{cc})$ & 1.91 \\
\hline & \multicolumn{2}{|c|}{$\Delta \mathrm{P}$} & 104.30 & \multicolumn{2}{|c|}{$\mathrm{VD}(\mathrm{cc})$} & 5.53 \\
\hline & $\mathrm{P} 1$ & 301.10 & $T(F)$ & 80.00 & Turn & 2.00 \\
\hline & $\Delta \mathrm{P}$ & 104.20 & $\mathrm{Z1}$ & 1.00 & Division & 17.00 \\
\hline & $\mathrm{P} 2$ & 196.90 & $\mathrm{Z2}$ & 1.00 & $\Delta \mathrm{V}(\mathrm{cc})$ & 1.91 \\
\hline 8 & & & 104.20 & & & 5.53 \\
\hline & $\mathrm{P} 1$ & 300.80 & $T(F)$ & 80.10 & Turn & 2.00 \\
\hline & $\Delta \mathrm{P}$ & 103.70 & $\mathrm{Z1}$ & 1.00 & Division & 17.00 \\
\hline & $\mathrm{P} 2$ & 197.10 & $\mathrm{Z2}$ & 1.00 & $\Delta \mathrm{V}(\mathrm{cc})$ & 1.91 \\
\hline 9 & & & 103.70 & & & 5.55 \\
\hline & P1 & 300.70 & $\mathrm{~T}(\mathrm{~F})$ & 79.90 & Turn & 2.00 \\
\hline & $\Delta \mathrm{P}$ & 103.50 & $\mathrm{Z1}$ & 1.00 & Division & 17.00 \\
\hline & $\mathrm{P} 2$ & 197.20 & $\mathrm{Z2}$ & 1.00 & $\Delta \mathrm{V}(\mathrm{cc})$ & 1.91 \\
\hline 10 & & & 103.50 & & & 5.56 \\
\hline
\end{tabular}


The same Statistical analysis was done for the ten series of the line volume measurement for section V1 to V2 tests to find a value for the final line volume. The results can be seen in Table C-4.

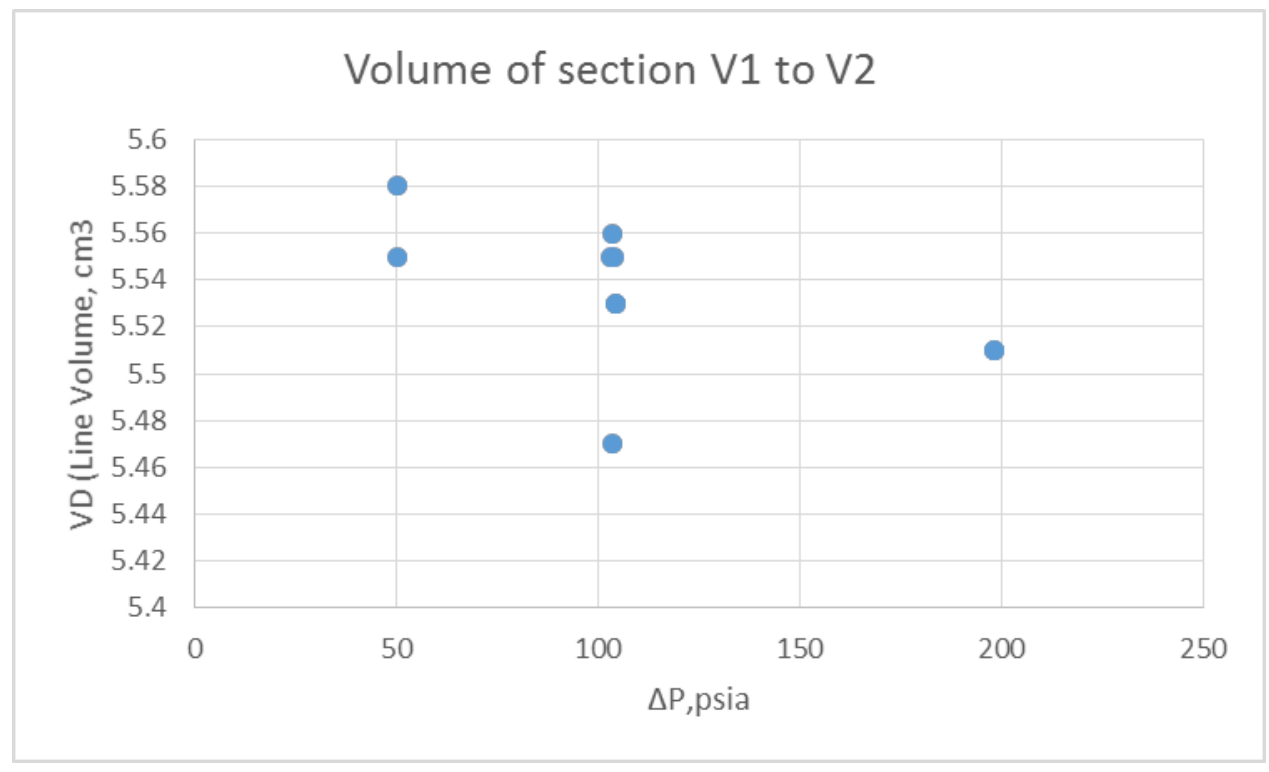

Figure C-2: Line Volume for Section $V_{1}$ to $V_{2}$

Table C-4: Statistical analysis for Section V1 to V2

\begin{tabular}{|l|r|}
\hline $\begin{array}{l}\text { Table C-4: Statistical analysis } \\
\text { for Section } \mathbf{V}_{\mathbf{1}} \text { to } \mathbf{V}_{\mathbf{2}} \text { Value }\end{array}$ & $\mathbf{c m}^{\mathbf{3}}$ \\
\hline Mean & 5.53 \\
\hline Standard Error & 0.01 \\
\hline Median & 5.54 \\
\hline Mode & 5.55 \\
\hline Standard Deviation & 0.03 \\
\hline Range & 0.11 \\
\hline Minimum & 5.47 \\
\hline Maximum & 5.58 \\
\hline Sum & 55.34 \\
\hline Count & 10.00 \\
\hline Confidence Level (95.0\%) & 0.02 \\
\hline
\end{tabular}


Regarding Table C-4, the volume of section $\mathrm{V}_{1}$ to $\mathrm{V}_{2}$ would be $5.53 \mathrm{~cm}^{3}$ with $0.03 \mathrm{~cm}^{3}$ of Standard Deviation.

Table C-5: Line volume measurement for section $V_{1}$ to $V_{6}$

\begin{tabular}{|c|c|c|c|c|c|c|}
\hline NO & \multicolumn{2}{|c|}{ Pressure, psi } & \multicolumn{2}{|c|}{ Compressibility factor (Z) } & \multicolumn{2}{|c|}{ Manual pump volume } \\
\hline \multirow[b]{4}{*}{1} & P1 & 203.40 & $\mathrm{~T}(\mathrm{~F})$ & 79.80 & Turn & 2.00 \\
\hline & $\Delta \mathrm{P}$ & 102.70 & $\mathrm{Z} 1$ & 1.00 & Division & 14.00 \\
\hline & $\mathrm{P2}$ & 100.70 & $\mathrm{ZZ}$ & 1.00 & $\Delta \mathrm{V}(\mathrm{cC})$ & 1.83 \\
\hline & \multicolumn{2}{|c|}{$\Delta \mathrm{P}$} & 102.70 & \multicolumn{2}{|c|}{$\mathrm{VD}(\mathrm{cc})$} & 3.62 \\
\hline \multirow[b]{4}{*}{2} & P1 & 222.60 & $\mathrm{~T}(\mathrm{~F})$ & 79.90 & Turn & 2.00 \\
\hline & $\Delta \mathrm{P}$ & 103.40 & $\mathrm{Z} 1$ & 1.00 & Division & 10.00 \\
\hline & $\mathrm{P2}$ & 119.20 & $\mathrm{ZZ}$ & 1.00 & $\Delta \mathrm{V}(\mathrm{CC})$ & 1.71 \\
\hline & \multicolumn{2}{|c|}{$\Delta \mathrm{P}$} & 103.40 & \multicolumn{2}{|c|}{$\mathrm{VD}(\mathrm{cc})$} & 3.69 \\
\hline \multirow[b]{4}{*}{3} & P1 & 221.90 & $\mathrm{~T}(\mathrm{~F})$ & 79.80 & Turn & 2.00 \\
\hline & $\Delta \mathrm{P}$ & 103.10 & $\mathrm{Z1}$ & 1.00 & Division & 9.00 \\
\hline & $\mathrm{P2}$ & 118.80 & $\mathrm{ZZ}$ & 1.00 & $\Delta \mathrm{V}(\mathrm{cc})$ & 1.69 \\
\hline & \multicolumn{2}{|c|}{$\Delta \mathrm{P}$} & 103.10 & \multicolumn{2}{|c|}{$\mathrm{VD}(\mathrm{cc})$} & 3.63 \\
\hline \multirow[b]{4}{*}{4} & P1 & 253.40 & $\mathrm{~T}(\mathrm{~F})$ & 80.00 & Turn & 2.00 \\
\hline & $\Delta \mathrm{P}$ & 102.50 & $\mathrm{Z1}$ & 1.00 & Division & 0.00 \\
\hline & $\mathrm{P} 2$ & 150.90 & $\mathrm{Z2}$ & 1.00 & $\Delta \mathrm{V}(\mathrm{CC})$ & 1.43 \\
\hline & \multicolumn{2}{|c|}{$\Delta \mathrm{P}$} & 102.50 & \multicolumn{2}{|c|}{ VD (cc) } & 3.53 \\
\hline \multirow[b]{4}{*}{5} & P1 & 261.20 & $\mathrm{~T}(\mathrm{~F})$ & 80.10 & Turn & 2.00 \\
\hline & $\Delta \mathrm{P}$ & 109.50 & $\mathrm{Z} 1$ & 1.00 & Division & 5.00 \\
\hline & $\mathrm{P2}$ & 151.70 & $\mathrm{Z2}$ & 1.00 & $\Delta \mathrm{V}(\mathrm{cc})$ & 1.57 \\
\hline & \multicolumn{2}{|c|}{$\Delta \mathrm{P}$} & 109.50 & \multicolumn{2}{|c|}{$\mathrm{VD}(\mathrm{cc})$} & 3.75 \\
\hline \multirow[b]{4}{*}{6} & P1 & 260.80 & $\mathrm{~T}(\mathrm{~F})$ & 79.90 & Turn & 2.00 \\
\hline & $\Delta \mathrm{P}$ & 109.30 & Z1 & 1.00 & Division & 3.00 \\
\hline & $\mathrm{P2}$ & 151.50 & $\mathrm{Z2}$ & 1.00 & $\Delta \mathrm{V}(\mathrm{cc})$ & 1.51 \\
\hline & \multicolumn{2}{|c|}{$\Delta \mathrm{P}$} & 109.30 & \multicolumn{2}{|c|}{$\mathrm{VD}(\mathrm{cc})$} & 3.61 \\
\hline \multirow[b]{4}{*}{7} & P1 & 274.30 & $\mathrm{~T}(\mathrm{~F})$ & 79.70 & Turn & 2.00 \\
\hline & $\Delta \mathrm{P}$ & 125.40 & $\mathrm{Z} 1$ & 1.00 & Division & 9.00 \\
\hline & $\mathrm{P} 2$ & 148.90 & $\mathrm{Z2}$ & 1.00 & $\Delta \mathrm{V}(\mathrm{cC})$ & 1.69 \\
\hline & \multicolumn{2}{|c|}{$\Delta \mathrm{P}$} & 125.40 & \multicolumn{2}{|c|}{$\mathrm{VD}(\mathrm{cc})$} & 3.69 \\
\hline \multirow[b]{4}{*}{8} & P1 & 274.20 & $\mathrm{~T}(\mathrm{~F})$ & 80.00 & Turn & 2.00 \\
\hline & $\Delta P$ & 125.10 & $\mathrm{Z1}$ & 1.00 & Division & 8.00 \\
\hline & $\mathrm{P2}$ & 149.10 & $\mathrm{Z2}$ & 1.00 & $\Delta \mathrm{V}(\mathrm{cc})$ & 1.66 \\
\hline & & & 125.10 & & & 3.63 \\
\hline & P1 & 303.40 & $T(F)$ & 80.00 & Turn & 2.00 \\
\hline & $\Delta \mathrm{P}$ & 141.20 & $\mathrm{Z} 1$ & 1.00 & Division & 10.00 \\
\hline & $\mathrm{P2}$ & 162.20 & $\mathrm{Z2}$ & 1.00 & $\Delta \mathrm{V}(\mathrm{CC})$ & 1.71 \\
\hline 9 & & & 141.20 & & cc) & 3.68 \\
\hline & P1 & 303.10 & $T(F)$ & 79.80 & Turn & 2.00 \\
\hline & $\Delta \mathrm{P}$ & 140.90 & $\mathrm{Z} 1$ & 1.00 & Division & 10.00 \\
\hline & $\mathrm{P2}$ & 162.20 & $\mathrm{ZZ}$ & 1.00 & $\Delta \mathrm{V}(\mathrm{CC})$ & 1.71 \\
\hline 10 & & & 140.90 & & cc) & 3.69 \\
\hline
\end{tabular}


The results for Section $\mathrm{V}_{1}$ to $\mathrm{V}_{6}$ are shown in Table C-5, and Figure C-3 and the statistical analysis is shown in Table C-6 suggests $3.65 \mathrm{~cm}^{3}$ for the volume of $0.06 \mathrm{~cm}^{3}$ of Standard Deviation.

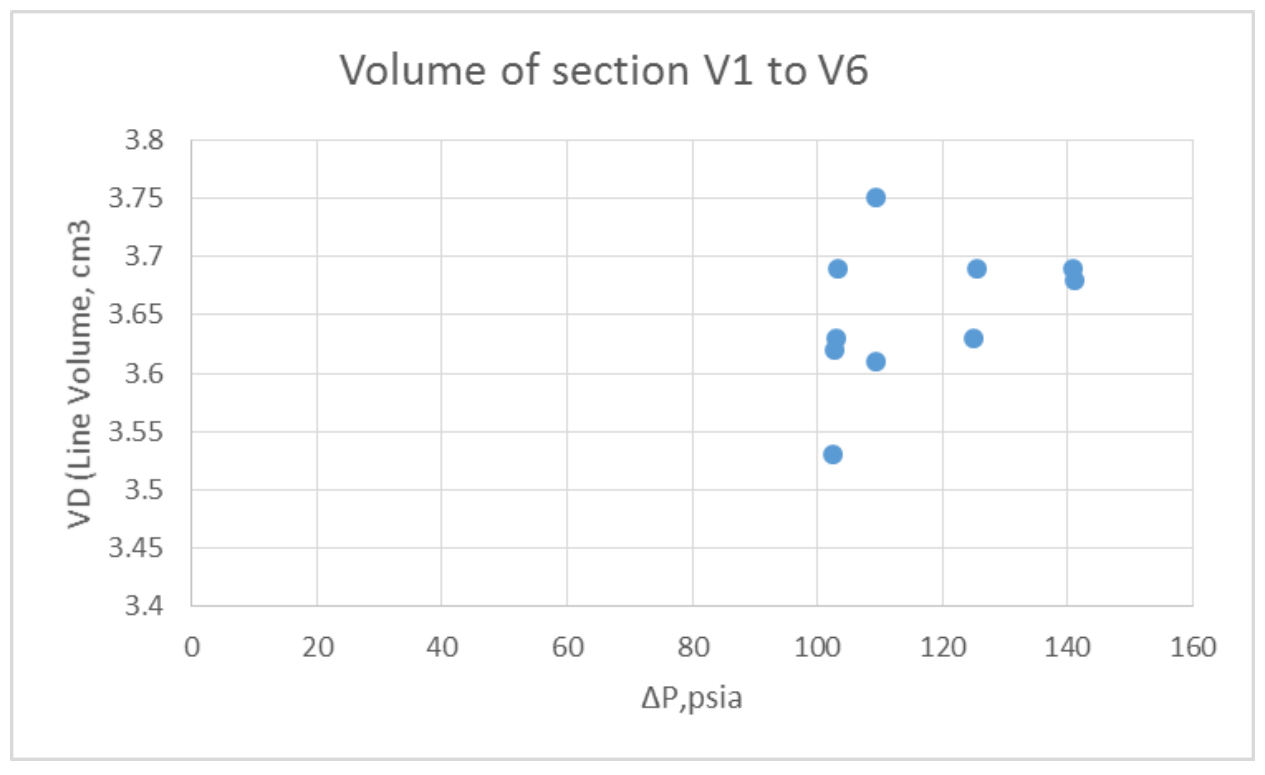

Figure C-3: Line Volume for Section $V_{1}$ to $V_{6}$

Table C-6: Statistical analysis for Section $V_{1}$ to $V_{6}$

\begin{tabular}{|l|r|}
\hline Value & $\mathbf{c m}^{\mathbf{3}}$ \\
\hline Mean & 3.65 \\
\hline Standard Error & 0.02 \\
\hline Median & 3.66 \\
\hline Mode & 3.69 \\
\hline Standard Deviation & 0.06 \\
\hline Range & 0.22 \\
\hline Minimum & 3.53 \\
\hline Maximum & 3.75 \\
\hline Sum & 36.52 \\
\hline Count & 10.00 \\
\hline Confidence Level (95.0\%) & 0.04 \\
\hline
\end{tabular}


The volume of section $\mathrm{V}_{6}$ to $\mathrm{PV}$, which is used for permeability calculations would be calculated by subtracting the volume of section $\mathrm{V}_{1}$ to $\mathrm{V}_{6}\left(3.65 \mathrm{~cm}^{3}\right)$ from the volume of section $\mathrm{V}_{1}$ to $\mathrm{PV}\left(20.2 \mathrm{~cm}^{3}\right)$, would give $16.55 \mathrm{~cm}^{3}$.

Final results of line volume measurement for porosity and permeability calculation are shown in Table C-7.

Table C-7: Line volume of each section

\begin{tabular}{|l|c|}
\hline Section & Volume, $\mathbf{c m}^{\mathbf{3}}$ \\
\hline $\mathbf{V}_{\mathbf{1}}$ to $\mathbf{V}_{\mathbf{2}}$ & 5.53 \\
\hline $\mathrm{V}_{\mathbf{6}}$ to $\mathbf{P V}$ & 16.55 \\
\hline $\mathbf{V}_{\mathbf{1}}$ to $\mathbf{P V}$ & 20.2 \\
\hline $\mathbf{V}_{\mathbf{1}}$ to $\mathrm{V}_{\mathbf{6}}$ & 3.65 \\
\hline
\end{tabular}




\section{Appendix D}

\section{Steady-State Flow Rate Validation Results}

Figure D-1 shows the example of an experiment with Helium for 50 cycles during three hours. Moreover, Figure D-2 confirms the linearity of the flow rate over time for one of the cycle's based on the R square test. Therefore $\mathrm{R}$ square test is used to check all cycles and eliminate these cycles has small R square. In addition, this linear flow as shown in Figure D3 allows us to apply Darcy's law to calculate the permeability.

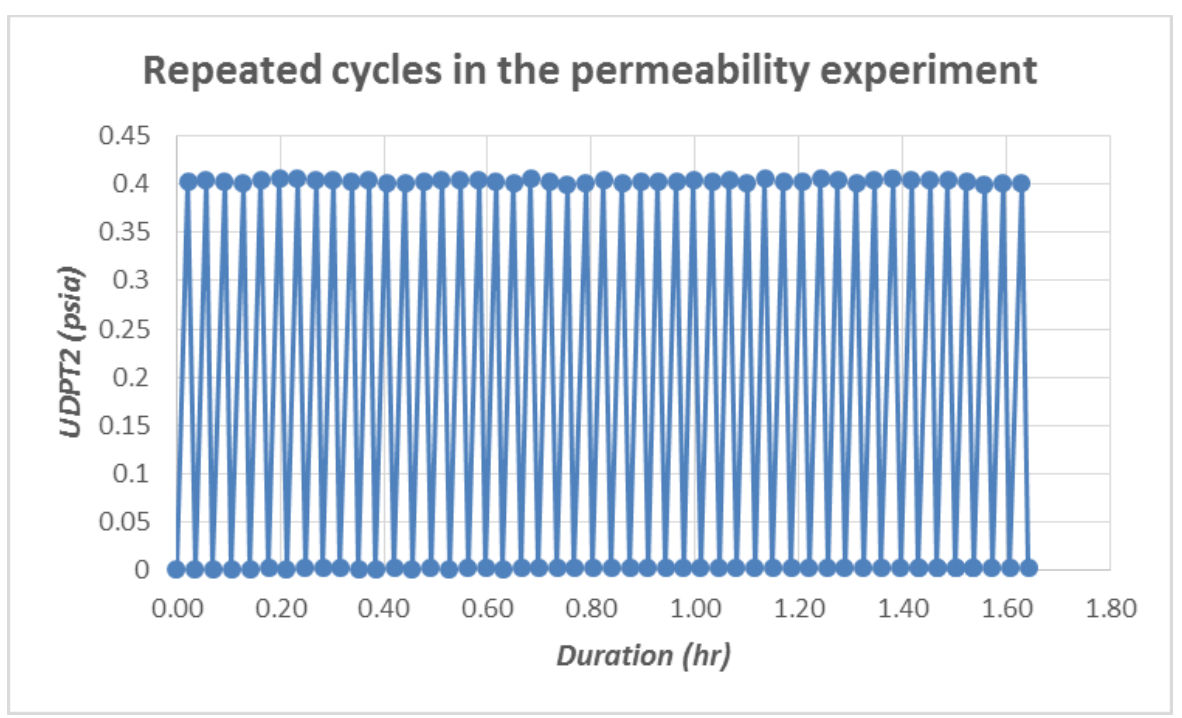

Figure D-1: Repeated cycles in a permeability experiment

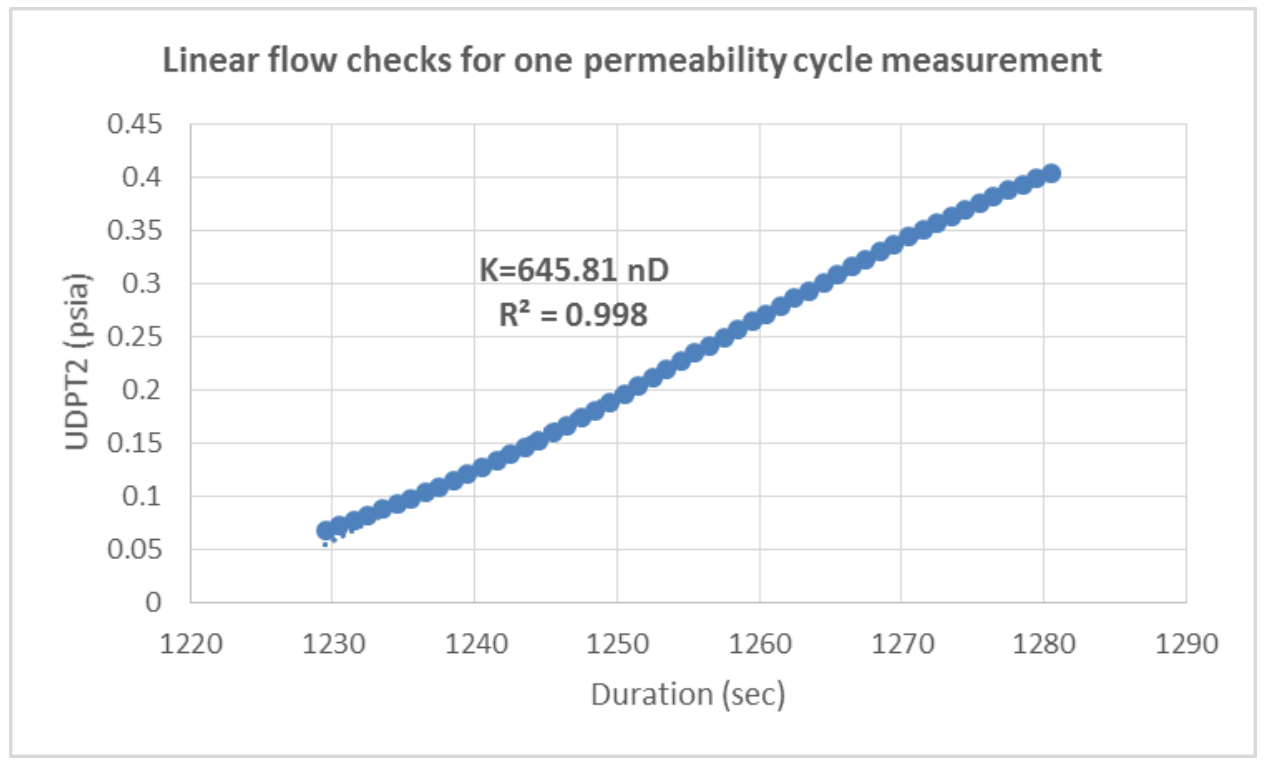

Figure D-2: Linear flow checks for one permeability cycle measurement 


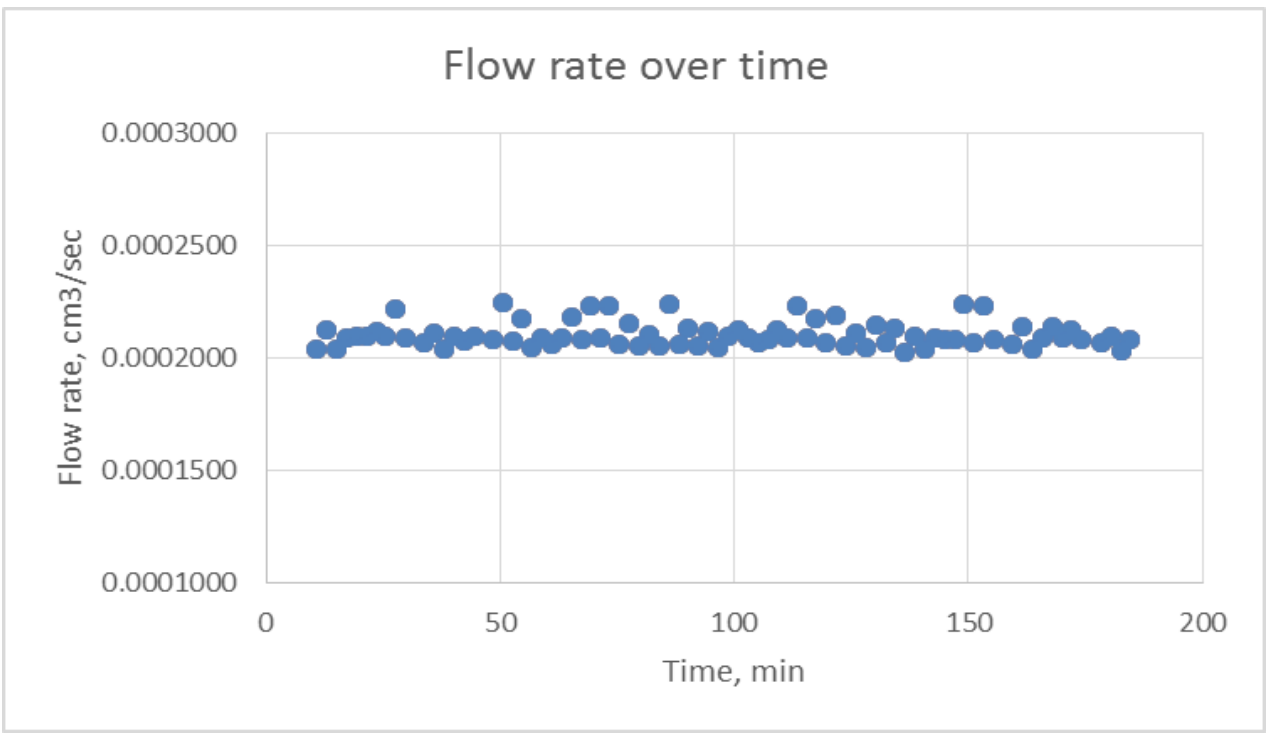

Figure D-3: Flow Rate Measurement (Helium) 